\title{
Evaluation of Rope Shovel Operators in Surface Coal Mining Using a Multi-Attribute Decision-Making Model
}

Ivana M. Vukotic

West Virginia University

Follow this and additional works at: https://researchrepository.wvu.edu/etd

\section{Recommended Citation}

Vukotic, Ivana M., "Evaluation of Rope Shovel Operators in Surface Coal Mining Using a Multi-Attribute Decision-Making Model" (2013). Graduate Theses, Dissertations, and Problem Reports. 176.

https://researchrepository.wvu.edu/etd/176

This Thesis is protected by copyright and/or related rights. It has been brought to you by the The Research Repository @ WVU with permission from the rights-holder(s). You are free to use this Thesis in any way that is permitted by the copyright and related rights legislation that applies to your use. For other uses you must obtain permission from the rights-holder(s) directly, unless additional rights are indicated by a Creative Commons license in the record and/ or on the work itself. This Thesis has been accepted for inclusion in WVU Graduate Theses, Dissertations, and Problem Reports collection by an authorized administrator of The Research Repository @ WVU. For more information, please contact researchrepository@mail.wvu.edu. 


\title{
Evaluation of Rope Shovel Operators in Surface Coal Mining Using a Multi-Attribute Decision-Making Model
}

\author{
Ivana M. Vukotic \\ Thesis submitted to the \\ Benjamin M. Statler College of Engineering and Mineral Resources \\ at West Virginia University \\ in partial fulfillment of the requirements \\ for the degree of \\ Master of Science \\ in \\ Mining Engineering
Vladislav Kecojevic, Ph.D., Chair
Christopher J. Bise, Ph.D.
Brijes Mishra, Ph.D.

Department of Mining Engineering

\author{
Morgantown, West Virginia \\ 2013
}

Keywords: rope shovel; operator evaluation; production rate; energy consumption; AHP; PROMETHEE II.

Copyright 2013 Ivana M. Vukotic 


\title{
ABSTRACT \\ Evaluation of Rope Shovel Operators in Surface Coal Mining Using a Multi-Attribute Decision-Making Model
}

\author{
Ivana M. Vukotic
}

Rope shovels are used to dig and load material in surface mines. One of the main factors that influence the productivity and energy consumption of rope shovels is the performance of the operator. Existing methods of evaluating operator performance do not consider the relationship between production rate and energy consumption. This thesis presents a method for evaluating rope shovel operators using the Multi-Attribute Decision-Making (MADM) model. Data used in this research were collected from an operating surface coal mine in the southern United States. The MADM model used in this research consists of attributes, their weights of importance, and alternatives. Shovel operators are considered the alternatives in the MADM model. The energy consumption model was developed with multiple regression analysis, and its variables are included in the MADM model as attributes. Formulation of the production rate model is already known, and thus determining the attributes that have a significant influence is straightforward. Preferences with respect to $\mathrm{min} / \mathrm{max}$ of the defined attributes were obtained with multi-objective optimization. Multi-objective optimization was performed with the overall goal of minimizing energy consumption and maximizing production rate. Weights of importance of the attributes were determined by using the Analytical Hierarchy Process (AHP). The overall evaluation of operators was performed by using one of the MADM models, PROMETHEE II. The research presented here may be used by mining professionals to help evaluate the performance of rope shovel operators in surface mining. 


\title{
Evaluation of Rope Shovel Operators in Surface Coal Mining Using Multi-Attribute Decision-Making Model
}

\author{
Ivana M. Vukotic \\ Thesis submitted to the \\ Benjamin M. Statler College of Engineering and Mineral Resources \\ at West Virginia University \\ in partial fulfillment of the requirements \\ for the degree of \\ Master of Science \\ in \\ Mining Engineering \\ Department of Mining Engineering
}

APPROVAL OF THE EXAMINING COMMITTEE

Vladislav Kecojevic, Ph.D., Chair

Christopher J. Bise, Ph.D.

Date

Brijes Mishra, Ph.D. 


\section{TABLE OF CONTENTS}

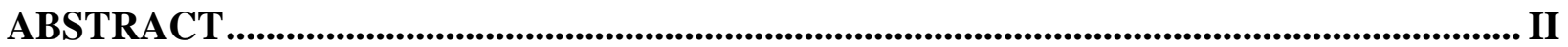

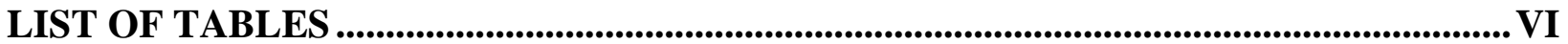

LIST OF FIGURES ...................................................................................................................... VII

ACKNOWLEDGEMENT...................................................................................................

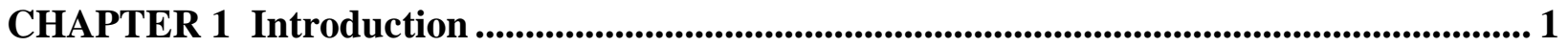

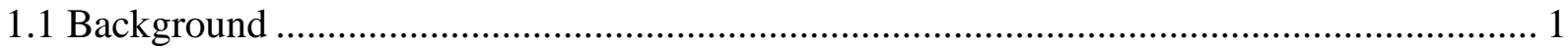

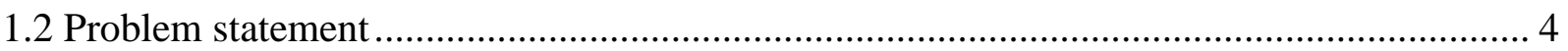

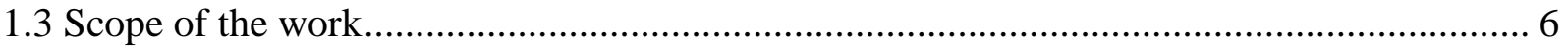

CHAPTER 2 Literature Review..................................................................................... 8

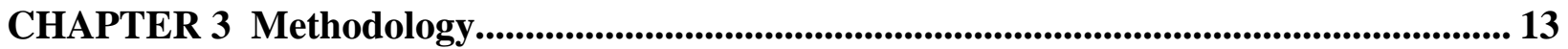

3.1 Introduction ...................................................................................................................... 13

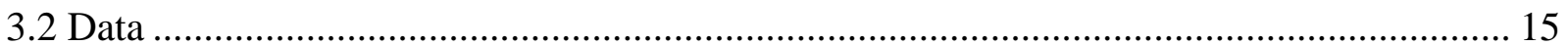

3.3 Development of the energy consumption and production rate model ................................ 17

3.3.1 Multiple linear regression model ................................................................................... 17

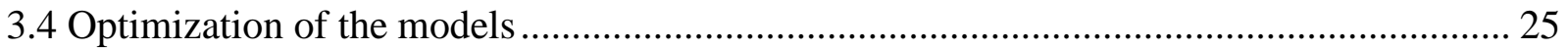

3.5 Multi-Criteria Decision Making methods ................................................................... 31

3.5.1 Basic characteristics of MADM models...................................................................... 34

3.5.2 Determining the weights of the criteria with Analytic Hierarchy Process .................... 35

3.5.3 Basic principles of PROMETHEE II method................................................................... 40

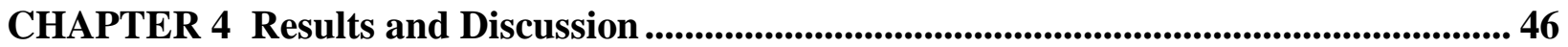

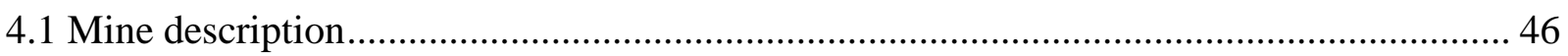

4.2 Statistical analysis of the measured parameters .................................................................. 48

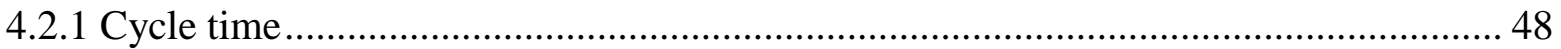

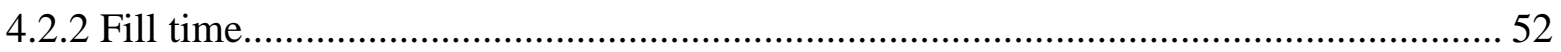




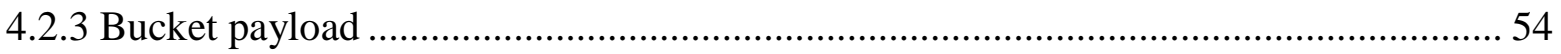

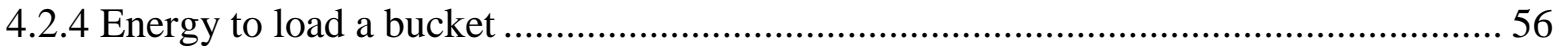

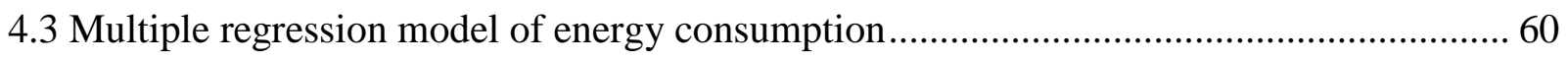

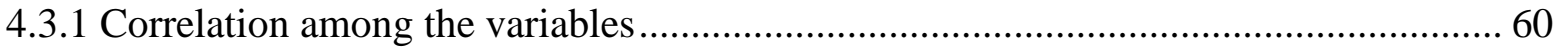

4.3.2 Best subsets and Stepwise regression analysis .................................................. 60

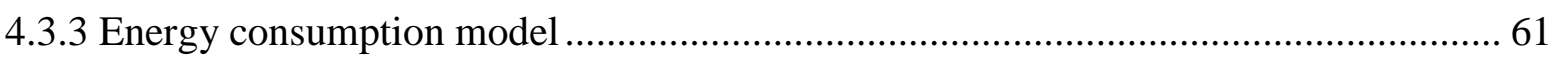

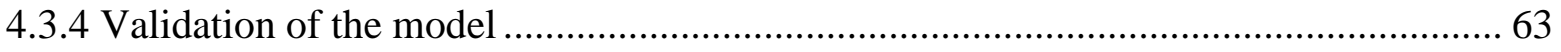

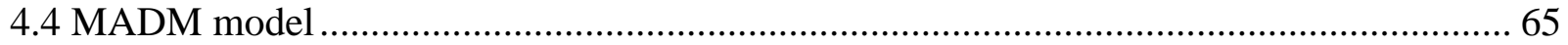

4.4.1 Obtaining the weights of the criteria in the MADM model with AHP ...................... 65

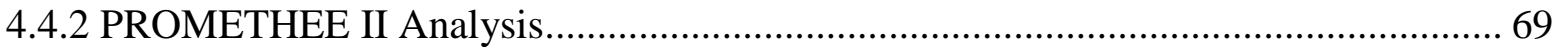

CHAPTER 5 Summary, Conclusions and Recommendations for Future Research........... 77

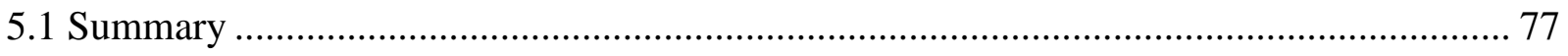

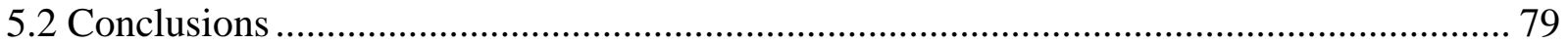

5.3 Recommendations for further research ............................................................... 82

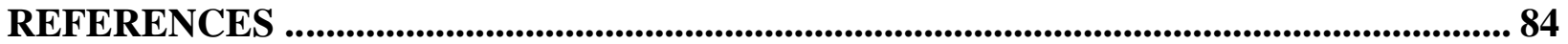




\section{LIST OF TABLES}

Table 3.1 Testing of significance of regression with analysis of variance ................................ 20

Table 3.2 Values of random consistency index for different size matrices .............................. 38

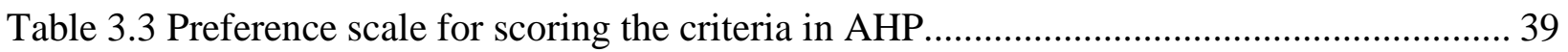

Table 3.4 Comparison matrix of the criteria in the model ..................................................... 39

Table 4.1 Mean and standard deviation of cycle time for each operator ................................. 50

Table 4.2 Mean and standard deviation of fill time for each operator.................................... 53

Table 4.3 Mean and standard deviation of payload for each operator ........................................ 55

Table 4.4 Mean and standard deviation of energy to load a bucket for each operator ................ 57

Table 4.5 Correlation between fill time, cycle time, volume of material in the bucket, and

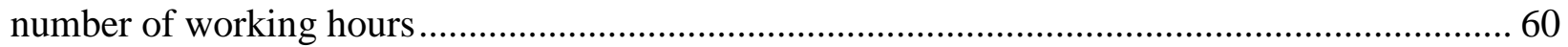

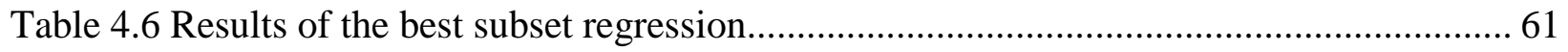

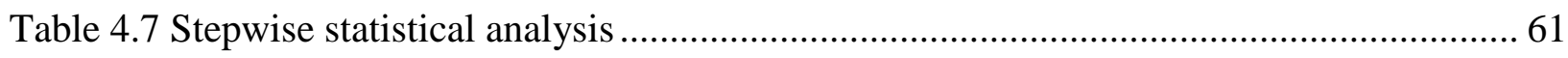

Table 4.8 Results of the multiple regression of energy consumption...................................... 62

Table 4.9 Analysis of variance table for energy consumption model...................................... 62

Table 4.10 Parameters for the regression and the validation model ........................................ 64

Table 4.11 Comparison matrix of the criteria in the model ..................................................... 66

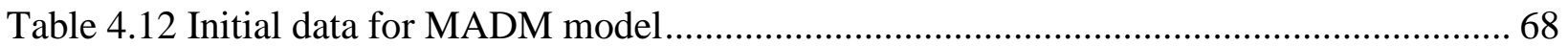

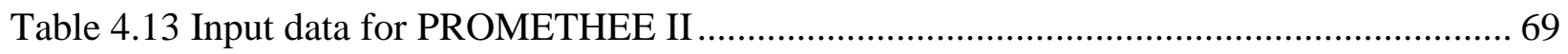

Table 4.14 Comparisons of Operator A with other operators................................................. 70

Table 4.15 Comparisons of Operator B with other operators ................................................. 71

Table 4.16 Comparisons of Operator C with other operators ............................................... 72

Table 4.17 Comparisons of Operator D with other operators................................................ 72

Table 4.18 Paired matrix of alternative comparisons ......................................................... 73

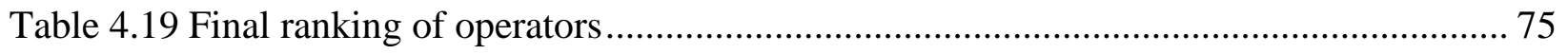

Table 4.20 Overview of mean production and energy consumption for shovel operators .......... 76 


\section{LIST OF FIGURES}

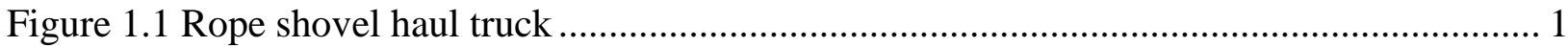

Figure 1.2 Energy consumption-related elements in mining ............................................. 2

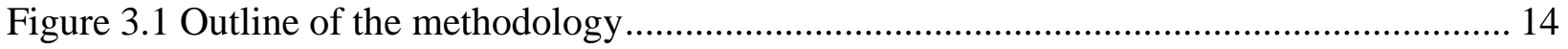

Figure 3.2 Graphical representation of general multi-objective optimization........................... 26

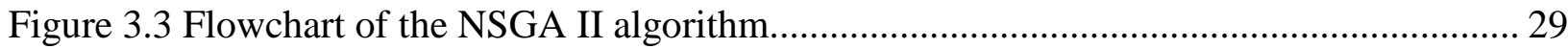

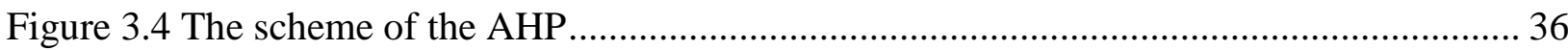

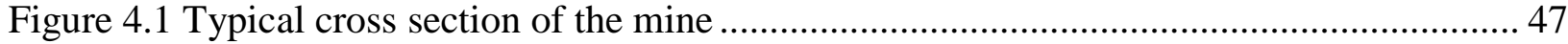

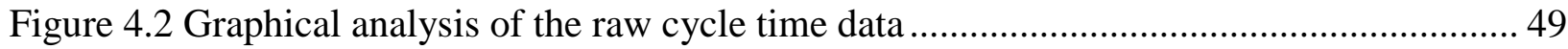

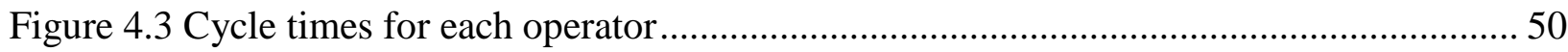

Figure 4.4 Relationship between mean production rate, mean fill factor, and mean cycle time for

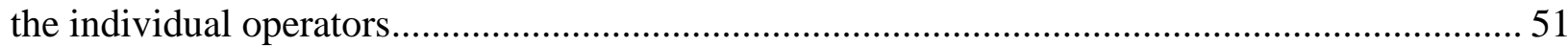

Figure 4.5 Graphical representation of the fill time data .................................................. 52

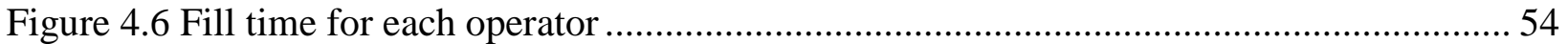

Figure 4.7 Histogram and boxplot of the payload ............................................................... 54

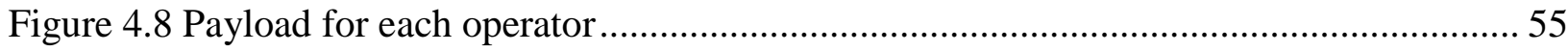

Figure 4.9 Histogram and boxplot of the raw energy data .................................................. 56

Figure 4.10 Energy to load a bucket for each operator........................................................ 58

Figure 4.11 Energy to load a bucket vs. fill time for each operator ......................................... 58

Figure 4.12 Relationship between mean fill factor, mean production rate and mean energy....... 59

Figure 4.13 Weights of the criteria for the MADM model...................................................... 66

Figure 4.14 Final ranking of operators with the flow values ................................................ 74 


\section{Acknowledgement}

I would like to thank my advisor, Dr. Vladislav Kecojevic, for his guidance, support, and encouragement to strive toward higher goals. Without his suggestions and high standards for research, I would not have been able to complete this thesis. Also, I'm grateful for the opportunity I’ve had to expand my knowledge as a graduate student.

I would like to thank my committee members, Dr. Christopher J. Bise and Dr. Brijes Mishra, for their valuable time spent for reviewing my thesis.

I would like to thank the coal mining industry for providing data for this research, and for financial assistance.

I would like to thank all my colleagues and friends in the mining engineering department for their friendship and help.

Finally, I would like to thank my parents and my sister, Milan Vukotic, Persida Vukotic, and Tijana Vukotic, who provided me with unconditional support and guidance throughout my graduate studies. 


\section{Chapter 1}

\section{Introduction}

\subsection{Background}

Rope shovels are used in large surface mining operations for the digging and loading of material (Figure 1.1). They are built with bucket sizes up to $100 \mathrm{yd}^{3}$.

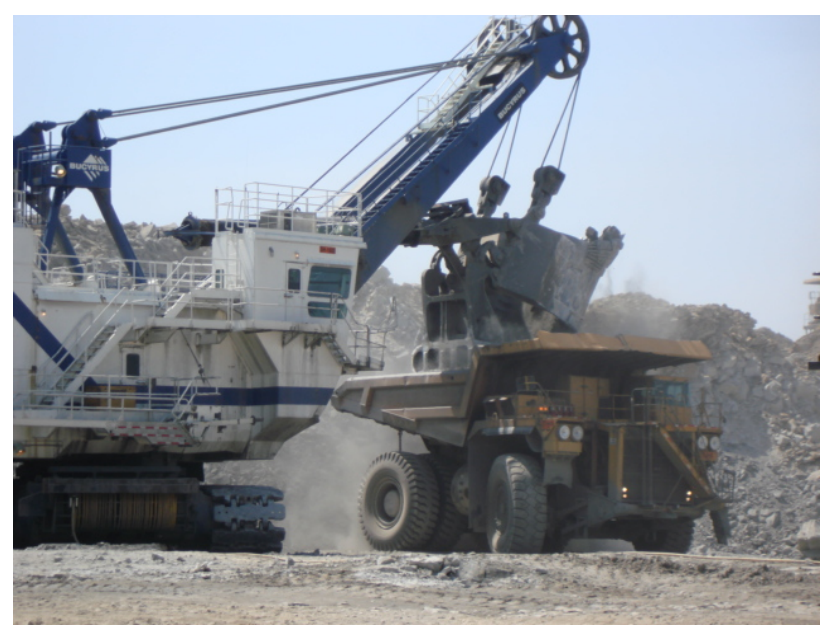

Figure 1.1 Rope shovel and haul truck

Shovel productivity is highly influenced by the skill and working practices of operators. According to Caterpillar (2010), one of the major factors for obtaining maximum productivity is a well-trained operator. Several research studies have shown that mine operating conditions and operators practices significantly affect energy consumption (Bernold 2007; Awuah-Offei and Frimpong 2010; Widzyk-Capehard and Lever 2004; Awuah-Offei and Summers 2010). Figure 1.2 illustrates elements that influence energy 
consumption in mining operations. It can be seen that the operator's experience and habits have a significant effect on energy consumption of the equipment. According to a mining energy bandwidth study (DOE 2007), investing in mining research and development, in addition to achieving best practices, could reduce energy consumption by approximately 69 billion kWh per year.

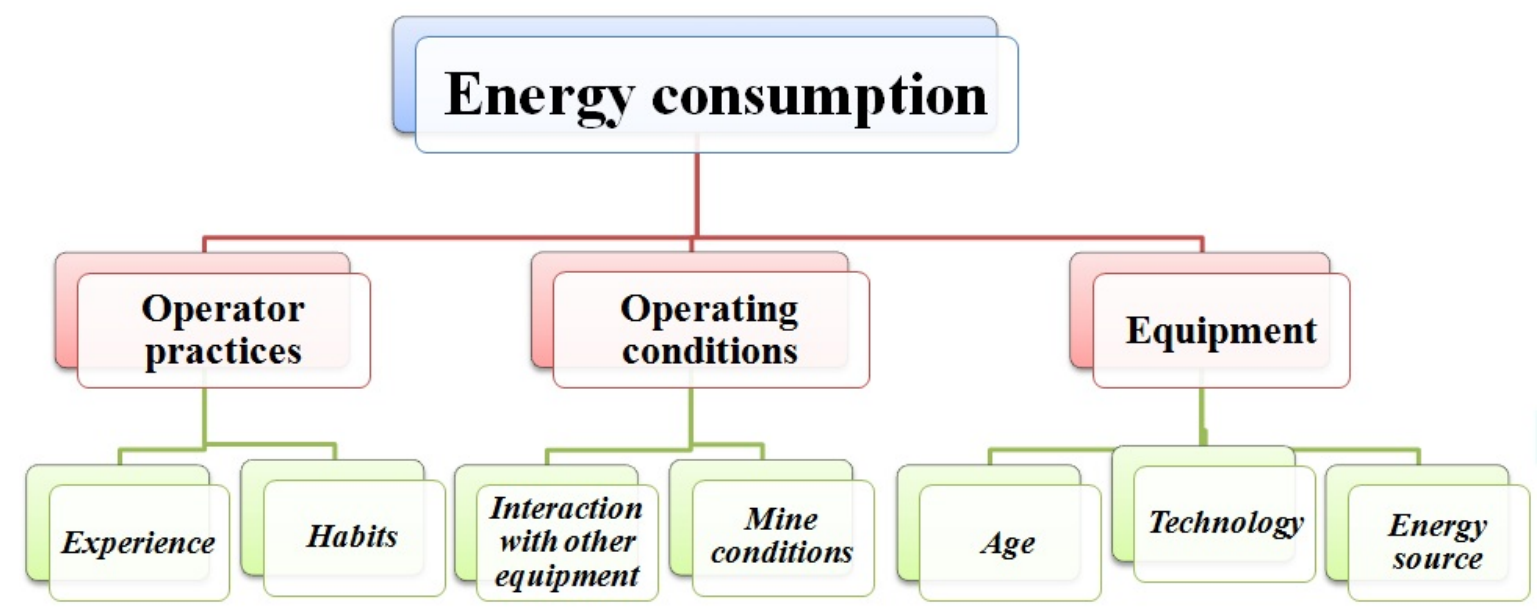

Figure 1.2 Energy consumption related elements in mining

(Awuah-Offei and Summers 2010)

Improvements in technology have increased efficiency in this field. These improvements include automation of rope shovel operation or, in some cases, technologies that provide operators with feedback on machine performance. This feedback is available through various monitoring systems that measure different shovel operational parameters. Collected information from these monitoring systems provides valuable insight about shovel performance to the operator. Thus, through constant monitoring of operator and shovel performance, mining professionals can analyze and find solutions for problematic parts of the overall cycle of the shovel. However, according to Lumley (2005), investing in 
technological improvements to the equipment is just a part of the overall improvement process.

There is a lack of quantitative models that evaluate operator performance. Particularly, there is a lack of models that consider the relationship between production of the shovel and energy consumption. The evaluation of operators is usually performed by observing different equipment-related tasks, and making intuitive judgments about how the operator performs. Also, operators are usually not tested and evaluated on personal characteristics such as reliability, team spirit, and job dedication (Lumley 2005). Likewise, companies determine how they are going to train operators and set evaluation parameters for the performance of the trainees.

In order to develop a model for the evaluation of operators, it is necessary to define the criteria to use to perform this assessment. Assessment should be based on parameters that are relevant to the production and energy consumption of the shovel. Some of the parameters will be more influential than the others. Thus, parameters identified as more important for production and energy consumption should be more emphasized in the evaluation process.

Since operator performance significantly affects performance of the shovel, it is important to analyze parts of the cycle that can be improved. The evaluation of shovel operators will help mining professionals develop strategies for improving productivity and energy efficiency, and for reducing the operating costs of shovels. 


\subsection{Problem statement}

According to Oborne (1993), when two components, man and machine, interact, a “...closed loop, error-correcting, information-transmitting system is developed, such that deviations from desired state are displayed by the system, interpreted by the operator, and corrected using controls.” Oborne (1993) points out that operator and machine depend on each other for harmonious and continued operation.

However, the individual is the one who controls the operation of the working system, and adjusts the machine toward his or hers own will and habits. According to Widzyk-Capehart and Lever (2004), the human factor is still the central part in the utilization of shovels. Peterson et al. (2001) state that people are becoming more and not less relevant to effective mining operations.

The most influential factors related to the overall working cycle of the shovel that impact its productivity are cycle time and fillability of the bucket. Also, average cycle time, swing angle, load, and bank condition depend on the operator's efficiency (P\&H 2003). High values of cycle time can indicate potential problems in the cycle. According to Fiscor (2007), better operator training and a consistent clean-up process around the loading area and face could save 20 minutes of cycle time per day.

The basic rope shovel motions involve hoist, crowd, swing, and propel. The shovel operating cycle consists of digging, swinging, dumping, returning, and positioning. Even though these parts of the operation are operationally independent, the skill and coordination of an operator is required for a smooth cycle.

The digging phase involves crowd motion of the bucket into the bank, hoist motion to fill the bucket, and drawing from the bank (P\&H Mine Pro Services 2001). When the bucket is 
hoisted to the bank, crowd and retract motion are used to control the depth of the bucket penetration. Penetration that is too shallow will lead to longer hoist travel distance needed to fill the bucket, which will increase the fill time of the cycle and decrease the fill factor. However, applying excessive crowd motion will make the hoist motion slower. The whole cycle time increases up to 50\%, or even more, when the bucket is stalled in the bank (P\&H Mine Pro Services 2001). Therefore, for an optimal and effective digging phase, it is mandatory for an operator to achieve balance between the hoist and crowd motion of the shovel. In addition, unbalanced crowd and hoist forces lead to jacking of the boom, which can cause serious damage to the shovel.

The swinging phase begins when the bucket is full of material, and in this phase, the operator controls the movement of the bucket though a defined swing path and dump height toward the haul truck. Since the swing represents the largest part of the overall cycle time, it should be kept to a minimum for maximum efficiency. An experienced operator can achieve smooth and continuous acceleration, maximum speed, and deceleration. Motion that is not smooth can result in the increase of time and spillage, which can further damage the body of the truck.

In addition, the operator influences the propel function, or positioning of the shovel in order to get the highest number of fill buckets before moving again. Locating the shovel too far from the bank can decrease available digging power. Also, inappropriate shovel location leads to an increase in cycle time. Maximum efficiency of the shovel is achieved when it is positioned close to the toe of the bank. According to P\&H Mine Pro Services (2001), by saving two minutes per operating hour on propelling, a 30-cubic-yard shovel could load one additional 170-ton truck per hour. 
The variation in the performance of operators could be the consequence of a poor management approach. Lumley (2005) states that in order to influence productivity, management has to understand workers, the job they do, and how they perceive that job.

Besides the lack of models for evaluating the productivity of operator performance, there is also a lack of research related to the relationship between shovel operator performance and the elements of cycle time, production rate, and energy consumption.

\subsection{Scope of the work}

The objective of this research is to develop a methodology to evaluate rope shovel operators with the goal of maximizing production rate and minimizing energy consumption. Decision-making models are used to achieve this objective. The solution of the decisionmaking problem is the selection from "the best" to "the weakest" operator where certain criteria are used for measuring quality of operator’s performance.

In order to solve the decision-making problem, the research goals are to:

* Find the appropriate multi-criteria decision model that deals with an already known, finite number of operators (alternatives). A multi-attribute decisionmaking model has been found to be suitable;

* Find the appropriate multi-attribute decision-making model that would provide ranking of operators from "the best" to "the weakest" in performance;

* Develop a model in order to determine which of the available measured parameters influence energy consumption; 
* Use parameters that influence energy consumption and production rate as criteria for measuring the quality of operator performance. In addition, determine weights of criteria;

* Find the preferences for parameters for achieving minimum energy consumption as well as maximum production rate;

* Construct a logical and easy-to-use model that would provide the evaluation of operators based on previously defined preferences.

The brief outline of the thesis can be presented as follows: (i) Chapter 1 includes a short introduction to the influence of the operator on the performance of the rope shovel, and an overview of the scope of the work; (ii) Chapter 2 includes a review of literature relating to already existing models and methodologies for the evaluation of operator performance; (iii) Chapter 3 includes the methodology used for ranking of operators based on their performance; (iv) Chapter 4 includes results and discussion on the applied outranking methodology; and (v) Chapter 5 includes conclusions and further recommendations related to the topic. 


\section{Chapter 2}

\section{Literature Review}

Sage (1984) indicates that a skilled performer is one who produces a fast and accurate output with a high consistency. However, according to Bernold (2007), this approach, which is based on behavioral observation, has two main shortcomings. One of them is that performance is not clearly related to skill, as other aspects—such as fatigue, motivation, boredom, temperature, and noise-can also affect performance. The second shortcoming is that this approach is qualitative in nature. Bernold (2007) suggests that motor skills of the operator are an essential component for everyday operations. Also, Robbins (2003) states that the aim is to understand how people differ in abilities and use that information to improve their performance.

Well-trained operator contributes to increased productivity. Today, automated equipment involves electronically sophisticated commands and accessories that ease the operation tremendously. Therefore, introducing controls that require minimal effort has changed the training requirements for operators. Also, work experience is positively correlated with skill. According to Harrel \& Daim (2010), motivation is particularly important for good performance; in fact, unmotivated employee contributes to decreased productivity and quality. Likewise, according to Peterson et al. (2001), good attitudes are important for high productivity. 
Operators become skilled in operating heavy equipment by actual practice or by using simulators made for coached training. Operators are usually evaluated by being observed in the performance of equipment-related tasks (Hard Hat Training 1990; Vista Training Inc. 2002; CareerTech 2008). Evaluations are performed by observation of operators engaging in duties such as: equipment inspection prior to operation, excavating operations, safety practices, grading, and leveling etc. Also, operators usually have to pass not only practical exams but written exams as well. The evaluator's judgment is based on how often the task is performed and how critical it is when it is irregularly performed. Both of these criteria are qualitative in nature and dependent on subjective judgment by the evaluator.

There are various simulators that are used for training operators. These simulators, for example, expose operators to a virtual rope shovel working in the common mining site with simulated mine trucks, dozers, and other pieces of equipment (Simlog 2012; Vista 2012; Dover Simulations 2012; Fifth Dimension Technologies 2011; Cybermine 2010). Training of operators is performed through simulation modules. Through each simulation module, productivity and quality of work are measured. Also, while using simulators, operators learn from their mistakes, as the simulators identify the least effective parts of their performance.

Weiss and Shanteau (2003) point out that using measurement instruments eliminates inconsistencies related to fatigue and bias associated with human operation. One of such examples would be using radar/ultrasound system as a position control system that would bring the bucket into the right position (Fiscor 2007).

Also, various systems have been developed that provide feedback about different rope shovel measured parameters. One of the most advanced shovel monitoring systems is 
Tritronics ShovelPro Shovel Monitor, developed by Thunderbird Mining Systems (2012) and used worldwide. This real-time monitoring system measures different shovel parameters such as bucket payload, coordinates of each bucket engaged, disengaged, dump point, and truck payload. The system gives the operator feedback about delays, positioning, and digging time, along with total production information (cycles, tons) in chronological order shift-wise. Accuweight by Drivers \& Control Services, Inc. (2003) is a similar system that measures shovel parameters; the operator gets immediate feedback from the interface system in order to increase shovel performance and productivity. In addition, for monitoring shovel teeth, the Canadian company Motion Metrics International Corp. (2012) developed ToothMetrics and WearMetrics. ToothMetrics uses an advanced image processing system along with the artificial intelligence algorithms to monitor shovel teeth continually, and prompts the operator when a shovel tooth or adapter is missing. WearMetrics provides the operator with constant information about shovel tooth wear by showing current length as a percentage of original length.

Bernold (2007) used a backhoe simulator for analyzing the motor skills of operators. At the beginning of the control cycle, the operator must decide what are further trajectories based on qualitative and quantitative feedback from the machine. The evaluation of the operator was conducted by analyzing his/her performance in regular operations while sensors were collecting data. Comparison of operators regarding their digging performance was performed with analysis of the digging forces, which were then used for calculating energy consumption. The operator's performance was estimated with respect to total energy per digging cycle, total path distance per digging cycle, and average velocity of the bucket. 
Another example of simulating operations of a rope shovel was carried out by AwuahOffei and Frimpong (2010). The task was carried out with the purpose of finding hoist rope and crowd arm speeds for optimal performance of the shovel. The simulator used algorithms for calculation of work done and resistive forces. Awuah-Offei and Frimpong (2010) pointed out that hoist rope and crowd arm speeds present fundamental actions for assessing of operator practices.

Patnayak (2006) used the average hoist and crowd power consumption of different teams of operators as a parameter for assessing the effect of operator practice on the performance of the shovel. According to Widzyk-Capehart and Lever (2004), operator digging technique has the direct influence on the stalling of the hoist during dig and slacking of the hoist ropes. Besides operator techniques, the performance was examined by analyzing productivity, operator cycle time, and techniques that operators practiced during the digging part of the cycle with respect to hoist/crowd utilization. Widzyk-Capehart and Lever (2004) pointed out that individual styles of operators have a significant impact on shovel productivity. Also, operator influence and behavior was examined while operating the rope shovel through a real-time feedback system.

The association between production rate and energy consumption association has been applied to the evaluation of dragline operators. Komljenovic et al. (2009) developed a methodology for evaluating dragline operators based on the relationship between production rate and energy consumption. This relationship is expressed as operator performance indicator. Operator performance indicator is defined as the ratio of hourly dragline production rate and hourly energy consumption. Operators are classified using confidence intervals of the operator performance indicator. 
The Analytical Hierarchy Process (AHP) was introduced by Saaty (1980) for modeling decision-making problems, which are subjective in nature and depend on multiple attributes in a hierarchical system. This process is simple and easy to understand, particularly where qualitative parameters have to be involved in the decision-making process. AHP is used in a wide variety of fields, including economics, corporate planning, quality management, etc. (Tzeng and Huang 2011). In surface mining, AHP is also a widely used model for equipment selection problems (Komljenovic and Kecojevic 2006; Bascetin, 2003; Yavuz 2007). Also, it has been applied to environmental studies (Bascetin 2006), mine design selection (Kluge and Malan 2011), and mine safety (Song and Hu 2009).

Some applications of AHP related to operator evaluation have included: Using fuzzy AHP, among other methods, to evaluate operator performance, based on qualitative and quantitative data, in order to make better decisions for operator allocations (Sen and Cinar, 2009); and selection of the best GSM operator for call center, human factor influence on overall equipment efficiency (Madhavan Pillai et al. 2011). One case in surface mining involved an assessment of dragline operator performance using AHP model (Bogunovic 2008).

The preference ranking organization method for enrichment of evaluations (PROMETHEE) is a model that is classified into the outranking family of Multi-Attribute Decision-Making models. The method was developed in the beginning of the 1980s and is widely used in different fields, including transportation, business, education, and healthcare. In mining engineering, this method was applied in the selection of the best underground ore transport system, and mineral prospectivity. However, not much data are available on using this method for ranking equipment operators. 


\section{Chapter 3}

\section{Methodology}

\subsection{Introduction}

In order to achieve the objective of this research, a multi-attribute decision making model (MADM) was used. Since the MADM models consist of attributes (criteria), their weights of importance (if necessary), and alternatives, different techniques were employed in developing this methodology. The first step was to derive energy consumption and production rate models. The energy consumption model was derived using a multiple regression tool. Production rate has an established method of formulation, based on the volume of material in the bucket and number of cycles. After defining the models, multiobjective optimization was performed using an evolutionary algorithm. Optimization was performed with respect to the minimization of energy consumption and maximization of the rate of production, using measured data on four rope shovel operators. In the next phase, the significant variables and their values obtained from the previous analyses were used for establishing the criteria for the MADM. The alternatives of the MADM were the rope shovel operators, while weights of the criteria were obtained from the AHP. Finally, the overall ranking of rope shovel operators was performed using one of the MADM models from the outranking family - PROMETHEE II. A detailed explanation of the methodology is explained in the following chapter. An outline of the methodology is presented in Figure 3.1. 
Defining alternatives of the MADM model

Defining criteria of the MADM model with preferences of minimizing energy consumption and maximizing production rate:

- development of regression model of energy consumption and production rate model

- optimization of energy consumption and production rate

Defining weights for the criteria in the model:

-AHP computations

Applying appropriate MADM model to obtain ranking of alternatives:

-PROMETHEE II computations

Making the decision - Outranking of operators from the best to the weakest performance

Figure 3.1 Outline of the methodology 


\subsection{Data}

Data used in this research were provided by a surface coal mine located in the southern part of United States. The shovel in this mine has an integrated AccuWeight real-time information monitoring system (Accuweight 2003), from which data were retrieved. The system contains sets of programmable logic controllers (PLCs) that monitor shovel parameters such as cycle time, fill time, payload, energy to load a bucket, etc. This system simultaneously samples 20-50 times per second and stores in database average values of 20 parameters per shovel cycle. Data flow involves cycle detection, payload weight, and input in a database (Accuweigh 2003). Measuring and recording events for a new cycle begins at the moment when the material in the bucket is dumped. Shovel parameters analyzed in this research are: cycle time, fill time, payload, and energy to load a bucket. Volume of the material in the bucket as well as fill factor are parameters that are calculated.

Cycle time is the time that the shovel needs to finish one loading pass. Cycle time starts when the bucket enters the muck-pile and starts digging. Cycle time consists of fill time, swing time, dump time, return time, and position time. This parameter highly influences productivity of the shovel. Fill time represents the digging phase of the cycle, and it refers to the time that the shovel spends loading the bucket.

Bucket payload is the true weight of the material in the bucket for each digging cycle. This parameter is characterized by the product of the volume of the material in the bucket $\left(\mathrm{yd}^{3}\right)$ and loose material density $\left(\mathrm{t} / \mathrm{yd}^{3}\right)$. Fill factor represents the ratio of the true loose material in the bucket and the rated bucket volume of the shovel. Like cycle time, this parameter greatly influences productivity of the shovel. Fill factor is used for defining material diggability. 
Energy that the shovel uses during the operation is related to the digging phase of the cycle time. Energy to load a bucket is recorded in a unit-less number format, which must be adjusted for providing energy consumption measured in kWh. For that purpose, conversion coefficients exist for different equipment and different applications.

Graphs of relationship between certain variables, provided as a part of statistical analysis in Chapter 4, have values that are transformed because of the different ranges of the variables. Thus, the variables are made dimensionless, which means that the values are brought down to the interval [0-1]. The method used for this transformation is vector normalization, where every value is divided with the norm. The norm represents a square root of the sum of the squares of the elements. 


\subsection{Development of the energy consumption and production rate model}

Based on the defined goal, the desirable evaluation of operators should be focused on the minimization of energy consumption as well as maximization of production rate. Therefore, both functions are defined first, where the function for calculating production rate is already known. In order to develop the function of energy consumption, relationships and significant variables were defined by statistical tests. The procedure used for developing this model was multiple regression modeling. Measured variables are used as independent ones (regressors) and included in the model development. These variables are: fill time (sec), cycle time (sec), volume of the material in the bucket $\left(\mathrm{yd}^{3}\right)$, and number of working hours (h).

\subsubsection{Multiple linear regression model}

Regression analysis is a statistical technique that is beneficial for examining the relationships between two or more variables, which is often the case in many engineering and science problems. Regression models can be used either for experimental or observational data. The general linear regression model is mathematically expressed with the following equation (Kutner et al. 2004):

$Y_{i}=\beta_{0}+\beta_{1} X_{i 1}+\beta_{2} X_{i 2}+\cdots+\beta_{p-1} X_{i, p-1}+\epsilon_{i}$

and

$$
\begin{array}{r}
\boldsymbol{E}(\boldsymbol{Y})=\boldsymbol{\beta}_{\mathbf{0}}+\boldsymbol{\beta}_{\mathbf{1}} \boldsymbol{X}_{\mathbf{1}}+\boldsymbol{\beta}_{2} \boldsymbol{X}_{\mathbf{2}}+\cdots+\boldsymbol{\beta}_{\boldsymbol{p}-\mathbf{1}} \boldsymbol{X}_{\boldsymbol{p}-\mathbf{1}} \\
\qquad \text { for } X_{i 0} \equiv 1 \text {, and } E\left(\epsilon_{i}\right)=0
\end{array}
$$


where:

$\boldsymbol{\beta}_{\mathbf{0}}, \boldsymbol{\beta}_{\mathbf{1}}, \ldots, \boldsymbol{\beta}_{\boldsymbol{p}-\mathbf{1}}$ are regression parameters,

$\boldsymbol{X}_{\mathbf{i 1}}, \ldots \boldsymbol{X}_{\boldsymbol{i}, \boldsymbol{p}-\mathbf{1}}$ are variables (regressors) in the model,

$\boldsymbol{\varepsilon}_{\boldsymbol{i}}$ is normal error term, which has to be independent and normally distributed with mean zero and variance $\sigma^{2}$, for appropriate adequacy of the model,

$\boldsymbol{E}(\boldsymbol{Y})$ is the expected value of the response variable Y.

Some models represent curvilinear and complex response functions, but they are still cases of general linear regression models. Linearity can be obtained by suitable transformation of the $\mathrm{Y}, \mathrm{X}_{\mathrm{i}}$ variables or both. The model of energy consumption is this model, where transformation of the response variable $\mathrm{Y}$ was performed (square root transformation).

Therefore, the general regression model with normal error terms shows that the observations $\mathrm{Y}_{\mathrm{i}}$ are independent normal variables, with mean $\mathrm{E}\left(\mathrm{Y}_{\mathrm{i}}\right)$ and constant variance $\sigma^{2}$. A statistical model for linear regression corresponds to the population regression line and a description of the variation of Y about the line (Moore and McCabe 2006).

The linearity of the model means that it is linear in its parameters, and does not refer to the shape of surface that is created. For the estimation of parameters, the method of least squares is used. Estimation of the variance of the error term $\sigma^{2}$ is a significant step in the linear regression, which the analysis of variance provides. 
For estimation of model adequacy in multiple linear regression problems, some hypotheses tests are useful. The suitable hypotheses are (Montgomery and Runger 2003):

$$
\begin{aligned}
& H_{0}=\beta_{1}=\beta_{2}=\cdots \beta_{k}=0 \\
& H_{1}: \beta_{j} \neq 0 \text { for at least one } j \\
& \text { where: }
\end{aligned}
$$

$\boldsymbol{H}_{\boldsymbol{o}}$ represents the null hypothesis,

$\boldsymbol{H}_{1}$ represents the alternative hypothesis.

Rejection of the null hypothesis indicates that at least one of the regressor variables $\mathrm{x}_{1}$, $\mathrm{x}_{2}, \ldots, \mathrm{x}_{\mathrm{k}}$ benefits significantly to the model. Total sum of squares $\left(\mathrm{SS}_{\mathrm{T}}\right)$ is the summation of the sum of squares considering regression $\left(\mathrm{SS}_{\mathrm{R}}\right)$ and sum of squares considering error $\left(\mathrm{SS}_{\mathrm{E}}\right)$. Test statistic for the null hypothesis defined with equation 3.3, is defined as following (Montgomery and Runger 2003):

$$
F_{0}=\frac{S S_{R} / p}{S S_{E} /(n-p-1)}=\frac{M S_{R}}{M S_{E}}
$$

where:

$\boldsymbol{F}_{\boldsymbol{o}}$ represents test statistic,

$\boldsymbol{p}$ represents the number of regressor variables in the model,

$\boldsymbol{n}$ represents the number of data used for analysis,

$M S_{R}$ represents the mean square model, and 
$\boldsymbol{M S}_{\boldsymbol{E}}$ represents mean square error.

The procedure is summarized in the analysis of variance (Table 3.1). These computations were performed with the Minitab statistical software.

Tests of the hypothesis on the individual regression coefficients contribute in determination of the potential value of every regressor variable in the model. Thus, the effectiveness of the model can be better if one or more regressor variables are included in the model, or can be better if one or more regressor variables are deleted from the model.

Table 3.1 Analysis of variance (Montgomery and Runger 2003)

\begin{tabular}{c|cccc}
\hline Source of variation & Sum of Squares & Degrees of Freedom & Mean Square & Test statistic $\boldsymbol{F}_{\mathbf{0}}$ \\
\hline Regression & $\mathrm{SS}_{\mathrm{R}}$ & $\mathrm{k}$ & $M S_{R}$ & $M S_{R} / M S_{E}$ \\
Error or residual & $\mathrm{SS}_{\mathrm{E}}$ & $\mathrm{n}-\mathrm{k}-1$ & $M S_{E}$ & \\
Total & $\mathrm{SS}_{\mathrm{T}}$ & $\mathrm{n}-1$ & & \\
\hline
\end{tabular}

The same rules are valid for reject/failure to reject the null hypothesis as for the already defined hypothesis testing. The test statistic for individual regressors is t-statistic, and it is provided in the regression output in statistical software. Another test that can be used for the same purpose is partial F-statistic, which plays a major role in model building (examination of the best subset of regressor variables for the model).

The p-values for individual variables assess the statistical significance of a particular regressor. For the confidence interval of $95 \%$, the p value should be less than $5 \%(0.005)$ in order to consider a particular variable significant. 
Coefficients of the multiple determination $\mathrm{R}^{2}$ or adjusted $\mathrm{R}^{2}$ are usually used as global statistics to evaluate the fit of the model. They can be mathematically expressed with the following equations:

$$
R^{2}=\frac{S S_{R}}{S S_{T}}, \quad R_{a d j}^{2}=1-\frac{s S_{E} /(n-p)}{S S_{T} /(n-1)}
$$

However, $\mathrm{R}^{2}$ can be somewhat problematic because it is always increasing with the addition of the variable in the model. On the other hand, $R_{\text {adj }}^{2}$ will have higher value only if the newly added variable reduces the error mean square. It is a particularly useful parameter in limiting the analyst for adding variables that are not useful in explaining variability of data.

The first step that should be undertaken in model building is the correlation test between the independent variables. The correlation coefficient measures the linear relationship between variables and has the value range from minus one to one. The value of minus one shows the perfect negative correlation, while the value of plus one shows the perfect positive correlation. In order to get the correlation among variables, Minitab software was used.

Next, one of the most important problems in regression analysis involves selecting the set of independent (regressor) variables to be used in the model.

The best subset analysis and stepwise regression analysis were used for determination of significant independent variables for development of the energy consumption model.

The selection of the "best" subset of the independent variables involves examining available variables in order to obtain the regression model. Thus, to make a model easy to use, as well as less costly, one's goal is to choose a few regressor variables as possible. For a 
$\mathrm{K}$ regressors $x_{1}, x_{2}, \ldots, x_{k}$ and a single response variable $y$ there are $2^{\mathrm{K}}$ total equations that should be analyzed. There are several criteria that can be used for evaluating and comparing those different possible regression models:

* $\mathbf{R}_{\mathbf{a d j}}^{2}$ - One of the most commonly used is the value of the adjusted coefficient of determination $R_{a d j}^{2}$. As previously explained, the model that maximizes this parameter, also minimizes the mean square error and, therefore, it is considered to be a suitable candidate for the best regression model.

* Cp - Another criterion that is used for evaluation of regression models is Cp statistic, which defines the total mean square error for the regression model. Therefore, the model that has minimum Cp statistic is considered to be the best regression model.

PRESS statistic - This statistic can also be used for evaluating different regressor models. This parameter gives a measure of how well the model will perform when predicting new data, or data that were not used for fitting the regression model.

Consequently, the best subset analysis was performed on all regressors that were available, and parameters $\mathrm{R}_{\mathrm{adj}}^{2}$ and Cp were used for evaluation of the most suitable model, which will be presented later in the thesis.

Besides the all possible regressor selection method, the stepwise regression technique was performed. This widely employed technique uses iterations to make a series of regression models by adding or removing variables at every step (Montgomery and Runger 2003). As previously mentioned, the criterion for adding or removing variables is usually a partial F-test. The process of the stepwise selection method begins with making one variable model, with the regressor that has the highest correlation with the response variable Y. In 
terms of statistics used for this analysis, this regressor will have the highest value of partial $\mathrm{F}$ statistic. Generally, at every step, the set of remaining regressors is examined, and the one with the largest partial F statistic is inserted into the model.

A different approach for selecting the best subset of variables is particularly useful in order to check if the same models result. However, it is suggested that if there are not a lot of candidate regressor variables, the recommended selection technique will be the best subset selection (Montgomery and Runger 2003). Also, this technique is not affected by dependencies between regressor variables.

In order to check if multicollinearity exits, the variance inflation factors (VIF) were calculated for the variables in the model. Multicollinearity represents dependency among the regressor variables, which has a serious effect on coefficients of the regression as well as appropriateness of the derived model. It is expressed with the Variance Inflation Factor (VIF), which has the following equation (Montgomery and Runger 2003):

$$
V I F=\frac{1}{\left(1-R_{j}^{2}\right)} \quad j=1,2, \ldots, k
$$

where:

$\boldsymbol{R}_{j}^{2}$ is the coefficient of multiple determination that is the result of regressing $\mathrm{x}_{\mathrm{j}}$ on the other $\mathrm{k}_{\mathrm{j}}$ regressors.

Some authors suggest that if the multicollinearity is less than 10 , it is not a problem. Others state that this value should not be more than 4 or 5 (Montgomery and Runger 2003). 
Applying all previously mentioned statistical procedures, the regression model for the energy consumption was developed and it is described in Chapter 4. Likewise, the model is required in the optimization part, and it is presented in that part of the thesis too.

As previously mentioned, the model of production rate is required for further analysis. Basically, it is the product of the volume of material in the bucket and number of cycles. It is usually expressed in terms of $\mathrm{yd}^{3} / \mathrm{h}$. The mathematical formulation of production rate can be defined as follows:

$$
Y=V B x \frac{3600}{C T}
$$

where:

$\boldsymbol{Y}$ represents production rate $\left(\mathrm{yd}^{3} / \mathrm{h}\right)$,

VB represents the volume of the material in the bucket $\left(\mathrm{yd}^{3}\right)$,

CT represents cycle time (sec).

Therefore, considering just maximization of production rate, the value of the volume of material in the bucket should be maximized, and the value of the cycle time should be minimized. However, building the model of energy consumption and also optimization of these two functions should be performed. 


\subsection{Optimization of the models}

Multi-objective optimization refers to a process of simultaneous optimization of two or more usually conflicting objectives with or without bounds and constrains. The term optimize (minimize or maximize) means to obtain a solution that provides the values of all objective functions, and that satisfies the decision maker. It is a widely used method in many different fields. Multi-objective optimization techniques provide a preferred solution or set of efficient solutions. Thus, in general, the optimum solution for multi-objective optimization is called a Pareto optimal solution, or several solutions called an optimal Pareto set (Figure 3.2). Since Multi-objective optimization, as a method, finds one or more optimum solutions of variables in objective functions, it is often used to assist the decision maker, and it is frequently an important component of the decision-making system. A generalized form of multi-objective optimization can be mathematically defined as (Diwekar 2008; Venkataraman 2003):

Minimize (or Maximize) $\bar{Z}=\left(Z_{1}, Z_{2}, \ldots, Z_{k}\right)$

$$
\begin{array}{rr}
\text { Subject to } & h(x)=0 \\
g(x) \leq 0 & \\
x_{i}^{l} \leq x_{i} \leq x_{i}^{u}, i=1,2, \ldots, n
\end{array}
$$

where $\bar{Z}$ represents the set of objective functions, $\mathrm{x}_{\mathrm{i}}$ are the decision variables, $h(x)$ set of equality constrains, $g(x)$ set of inequality constraints, and $x_{i}^{l} \leq x_{i} \leq x_{i}^{u}, i=1,2, \ldots, n$ represent side constraints. Both objective functions and equality and inequality constraints are mathematical functions that depend on decision variables. Side constraints represent a significant part of the solution mechanism because they express the range of design 
variables. Every design variable must have bounds, which are lower-limit and upper-limit numerical values.

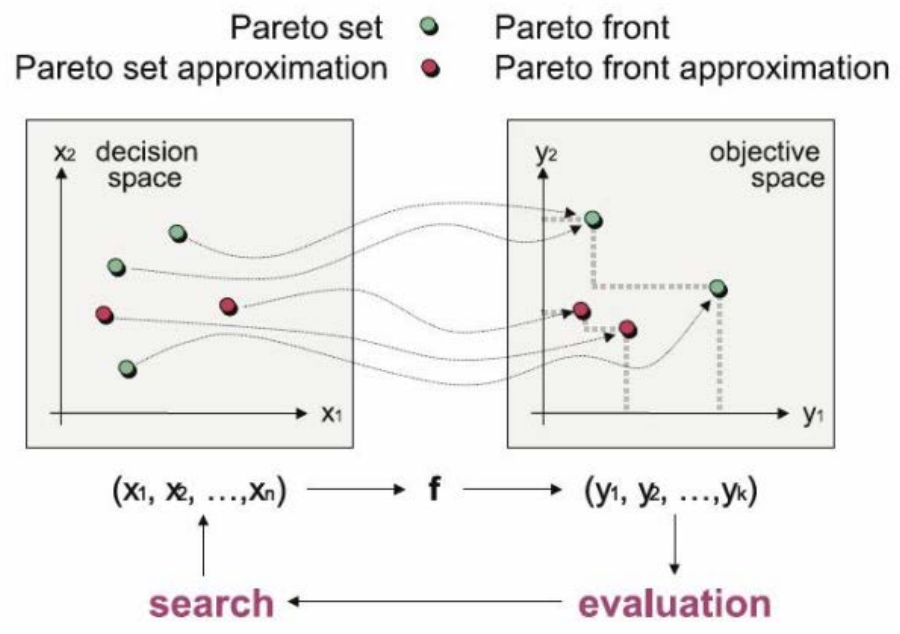

Figure 3.2 Graphical representation of general Multi-objective optimization problem

(Zitzler et al. 2004)

Considering the goal of this research, optimization of two functions was performed. Multi-objective optimization was performed in order to determine optimal values of measured parameters on a given rope shovel. The optimal values of these parameters will provide information about which of the variables should be minimized or maximized, which is a requirement for further analysis. These variables will be attributes in the MADM model. The information about minimization or maximization of criteria, which will be later defined, is a mandatory part of the set-up for the MADM model.

Two optimization functions in this model are:

energy consumption per hour in unit-less number,

production rate $\left(\mathrm{yd}^{3} / \mathrm{h}\right)$ 
As previously explained, the function of energy consumption is developed with regression analysis, with the variables in the model: fill time (sec), cycle time (sec), volume of the material in the bucket $\left(\mathrm{yd}^{3}\right)$, and number of working hours (h). Production rate depends on two measured variables: volume of the material in the bucket $\left(\mathrm{yd}^{3}\right)$ and number of cycles. This optimization does not have any constrain functions, but only the side constrains (bounds). The bounds of optimization are taken as minimum and maximum values of data for those variables.

Therefore, the set-up for this optimization problem can be presented as follows:

$$
\begin{aligned}
& \operatorname{Minimize} Z_{1}(x)=Z_{1}\left(x_{1}, x_{2}, x_{3}, x_{4}\right) \\
= & \left(1007.35+56.22 * x_{1}-17.68 * x_{2}+7.46 * x_{3}-8.81 * x_{4}\right)^{2} \\
& \text { Maximize } Z_{2}(x)=Z_{2}\left(x_{3}, x_{2}\right)=x_{3} *\left(\frac{3600}{x_{2}}\right)
\end{aligned}
$$

Bounds $7.57 \leq x_{1} \leq 12.77,27.72 \leq x_{2} \leq 43.97,14 \leq x_{3} \leq 60,0.5 \leq x_{4} \leq 5.4$;

where $Z_{1}(x)$ represents energy consumption, $Z_{2}(x)$ represents production rate $\left(\mathrm{yd}^{3} / \mathrm{h}\right), \mathrm{x}_{1}$ is fill time, $\mathrm{x}_{2}$ is cycle time, $\mathrm{x}_{3}$ is volume of the material in the bucket, and $\mathrm{x}_{4}$ is number of working hours.

The process of multi-objective optimization was performed with the evolutionary algorithm. Evolutionary algorithms are popular concepts for solving multi-objective optimization scenarios. These algorithms are search algorithms that emulate the process of evolution in order to find the best solution. Though the basic concept of them is simple, they have proven to be robust, general, and effective search mechanisms (Back et al. 1997). 
These algorithms have features that are highly desirable for solving problems that include multiple conflicting objectives and large, notably complex search spaces.

One of the evolutionary (genetic) algorithms that represents a standard approach to solving multi-objective optimization is Non-dominated Sorting Genetic Algorithm-II (NSGA-II), which is used in this research. NSGA-II starts with the initialization of the population, with respect to a range of the problem and constrains (if any). This population is then sorted and characterized by non-domination into each front. For sorting the population of size $\mathrm{N}$ for a given level of non-domination, the comparison of every solution with every other solution must be performed, to see if it is dominated. This process gives all individuals in the first non-dominated front. Next, the first non-dominated front is followed by the second front, which is dominated only by the first front, and so on, following the same procedure. Every individual in every front has rank (fitness) value, or it is characterized by its front. Thus, the individual from the first front has a rank value of 1 , from the second front a rank value of 2, etc. Also, every individual has crowding distance, which is assigned by front.

Estimation of crowding distance is essentially an estimation of density of solutions enclosing a particular point in the population. This distance is estimated by averaging the distance of two points on either side of the particular point in the population along each of the objectives. If crowding distance is a large number, the population will have better diversity. In regards to crowding distance, as well as rank of the individual, the parents are selected from the population. The selected population creates offsprings from crossover and mutation operators. The next generation is formed by the combination of the parent and 
offspring population, and it is further sorted according to non-domination. The graphical representation of the NSGA-II is shown in the Figure 3.3.

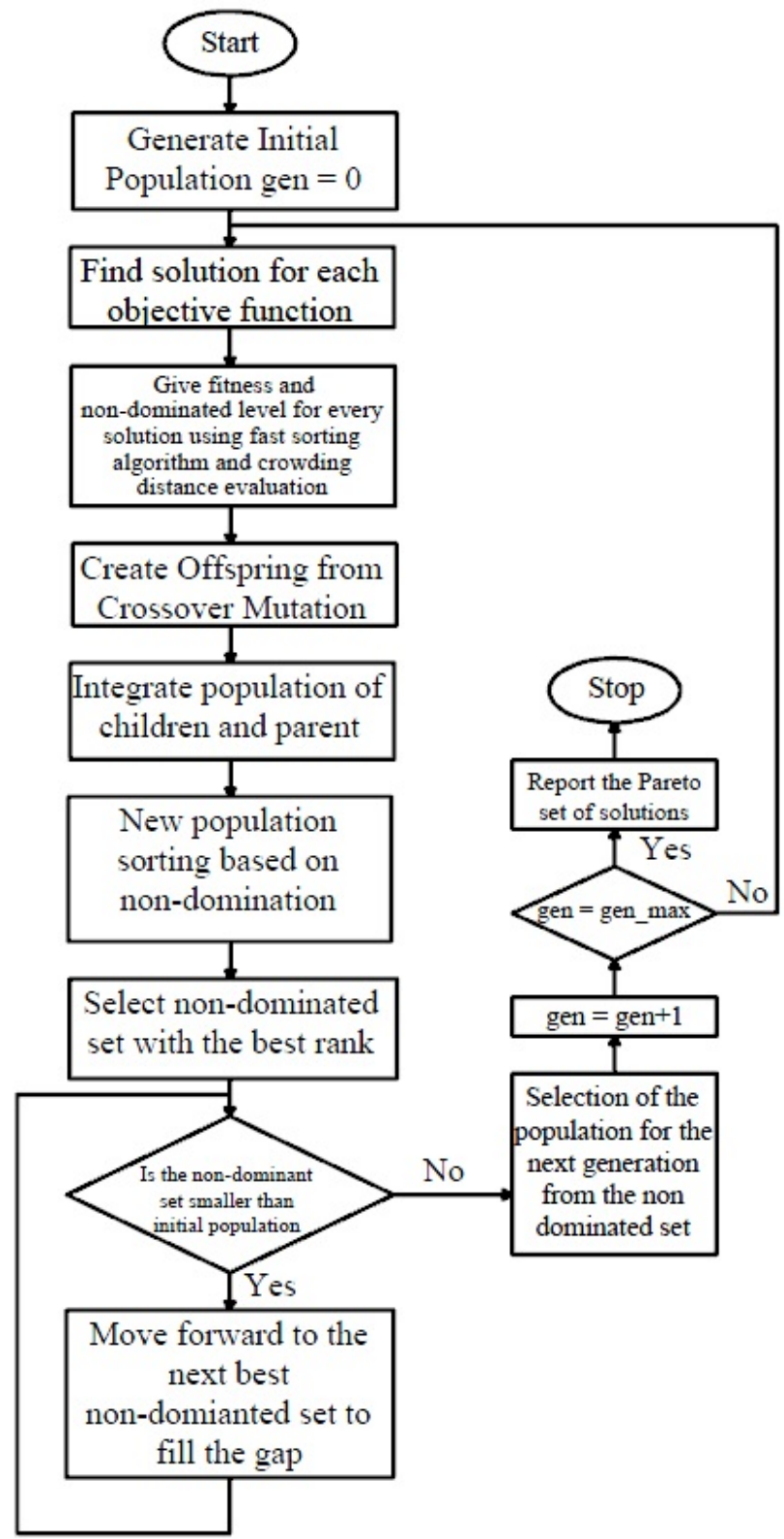

Figure 3.3 Flowchart of the NSGA II algorithm (Balaji and Kamaraj 2012) 
Optimization is performed with the GANetXL add-in for Microsoft Excel. The variables defined as genes in the software wizard are fill time, cycle time, volume of material in the bucket, and number of working hours. All of the genes are real numbers whose values are within the range of their minimum and their maximum value (upper bond and lower bond). Objectives are production rate $\left(\mathrm{yd}^{3} / \mathrm{h}\right)$, which is set to be maximized, and energy consumption, which is set to be minimized.

The choice of crossover can impact the effectiveness of the genetic algorithm. Crossover happens by joining the chromosome at a particular point(s) on every chromosome, and then rearranging one part of chromosome A with the opposite part of chromosome B. For this particular optimization, simple multi-point crossover was chosen, because according to the authors of the software, it leads to a better distribution of genes across the offspring.

For the given setting and the bounds, multi-objective optimization provided the following results: minimum value of fill time, minimum value of cycle time, maximum value of volume of material in the bucket, and maximum value of number of working hours. This information was further used for the setting up the MADM model. 


\subsection{Multi-Criteria Decision-Making methods}

In problems where there are more than one criterion that represent performance of the alternative, Multi-Criteria Decision-Making (MCDM) is considered. Thus, this method is used to support the decision maker where multiple criteria are used for solving the problem. Usually, there is not an optimal solution for these problems, and the preferences of the decision maker characterize the difference between solutions.

Based on whether the solutions and alternatives are explicit or implicit in nature, MCDM are divided in two major groups of methods: Multi-Objective Decision-Making and MADM. MADM consider problems that have finite number of alternatives that are explicitly known from the beginning of the solution process. Every alternative is characterized with its performance in multiple criteria. In Multi-Objective Decision-Making a finite number of explicit constrains (functions) characterize an infinite number of alternatives (Vassilev et al. 2005).

For the ranking of operators from "the best" to "the weakest," MADM is a more appropriate method because of the following characteristics:

* explicit attributes,

* finite number of alternatives (discrete), selection and evaluation of the solutions that are already known.

Decision-making processes have several steps in the process of solving the particular problem (Tzeng and Huang 2011):

problem identification, set-up of preferences, 
evaluation of alternatives, and

determination of the best alternative.

Despite the problem that needs to be resolved (pre-determined goal), problem identification is related to definition of desirable criteria (attributes) as well as the number of alternatives that will be compared in regard to those given criteria. Furthermore, based on preferences of the decision maker to reach a pre-determined goal, the criteria should be minimized or maximized. Finally, with analysis of data with suitable techniques, selection of the appropriate model is performed in order to help the decision maker to evaluate, outrank, or improve possible alternatives.

The flow of solving a decision-making problem related to this research has the following steps:

* classification of rope shovel operators based on given attributes (problem identification);

* minimize energy consumption and maximize production rate, with respect to the measured parameters: cycle time, fill time, volume of the material in the bucket (setting up of the preferences);

* alternatives - Operator A, Operator B, Operator C and Operator D - evaluation based on the given preferences and weights;

* determination of the best operator, as well as ranking of other operators.

The mathematical model for solving MADM problems is formulated as following (Nikolic and Borovic 1996): 


$$
\operatorname{Max} \text { or } \operatorname{Min}\left\{\mathbf{f}_{1}(\mathbf{x}), \mathbf{f}_{2}(\mathbf{x}), \ldots, \mathbf{f}_{\mathbf{n}}(\mathbf{x}), \mathbf{n} \geq 2\right\}, x \in A\left(\mathbf{a}_{1}, \mathbf{a}_{2}, \ldots, \mathbf{a}_{m}\right)
$$

where:

$\mathbf{f}_{\mathbf{n}}(\mathbf{x})$ represents criteria (attributes),

n represents the number of criteria (attributes),

$\mathbf{a}_{\mathbf{i}}$ represents the alternatives in the model,

A represents set of all alternatives,

m represents the number of alternatives.

Values of all given criteria $\mathrm{f}_{\mathrm{n}}(\mathrm{x})$ are known, for every given alternative

$$
\mathbf{f}_{\mathbf{i j}}=\mathbf{f}_{\mathbf{j}}\left(\mathbf{a}_{\mathbf{i}}\right) \quad \forall(\mathbf{i}, \mathbf{j}) ; \mathbf{i}=1,2 \ldots, \mathbf{m} ; \mathbf{j}=1,2, \ldots, \mathbf{n} .
$$

It is common to present an MADM model as an appropriate decision matrix, where every row represents one alternative, and every column one criterion (attribute). The element of the matrix $f_{i j}$ represents performance of the alternative $a_{i}$ considering the criterion $f_{j}$. For $n$ criteria and $\mathrm{m}$ alternatives, the form of the matrix is shown in the equation (3.12). Values $\mathrm{w}_{\mathrm{i}}$ represent weights of given criteria defined by a decision maker or in some other way, with the rule that their summation must be equal to one. Minimization criteria can be translated to the maximization criteria multiplying with -1 .

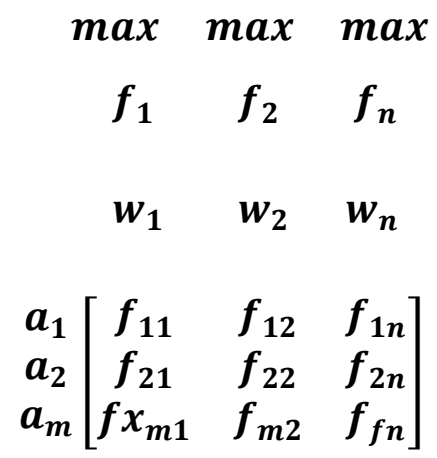




\subsubsection{Basic characteristics of MADM models}

Basic characteristics of the MADM model can be formulated as follows:

alternative (action) is dominant on other alternatives if $f_{j}\left(a_{s}\right) \geq f_{j}\left(a_{k}\right) \forall j=$ $1,2, \ldots, \mathrm{n} ;$ and $\forall \mathrm{k}=1,2, \ldots, \mathrm{m} ; \mathrm{s} \neq \mathrm{k}$. In other words, alternative $\mathrm{a}_{\mathrm{s}}$ is better than others in at least one attribute, and it is not worse in any attribute from all other alternatives;

* If there is a dominant alternative (action), then there is the perfect (optimal) solution which is that alternative. In that case, there is no need for the MADM model to choose the best alternative. However, problems of this type do not generally have a dominant alternative; in fact, even if there is a perfect solution, in order to rank and sort the other alternatives, further analysis must be conducted. Also, there may be a situation in which one of actions is dominant only on one of few of the other actions, but not on each of them;

alternative $\mathrm{a}_{\mathrm{q}}$ is non-dominated if there is not any other alternative $\mathrm{a}_{\mathrm{v}}$ for which it is true:

$$
\begin{aligned}
& f_{j}\left(a_{v}\right) \geq f_{j}\left(a_{q}\right) \forall j=1,2, \ldots, n ; \forall v=1,2, \ldots, m ; v \neq q \\
& \text { and } f_{j}\left(a_{v}\right)>f_{j}\left(a_{q}\right), \text { for at least one } j
\end{aligned}
$$

* alternatives $\mathrm{a}_{\mathrm{t}}$ and $\mathrm{a}_{\mathrm{v}}$ are equivalent if they have the same values for all attributes $f_{j}\left(a_{t}\right)=f_{j}\left(a_{v}\right), \forall j=1,2, \ldots, n ;$

* alternative $\mathrm{a}_{\mathrm{r}}$ is dominated if at least one of the other alternatives is better than $\mathrm{a}_{\mathrm{r}}$. 
For all MADM models, regardless of the method that is used, other important features also include quantification of qualitative attributes (not present in this research), modification of attributes of the same criteria, linearization and normalization of attributes, and definition of weights of criteria. In the case of qualitative data, transformations are mandatory, while in the case of the different nature of the data, they are recommended.

\subsubsection{Determining the weights of the criteria with AHP}

AHP is one of the most used and known additive weighting method applied in solving MADM problems for dealing with multiple criteria simultaneously. This method considers total aggregation between criteria and involves a linear additive model (Kasperczyk and Knickel 2004). It was proposed as a part of this research to set up weights for the criteria used in the MADM model.

All decision problems are resolved as hierarchical systems. First, these systems indicate defining the goal for the specific problem. Next, the goal is represented by several criteria, which can be further deconstructed into other sub-criteria. Therefore, the major steps of AHP can be defined as follows (Figure 3.4):

Deconstruction of the goal (problem) into a hierarchy of interrelated elements, thus constructing a hierarchical system. The simplest form of this structure has a top level-goal, intermediate level-criteria, and lowest level-options. This arrangement gives an overview of the complexity of the relations and shows the decision maker whether the elements in the each level are of the same size for correct comparison (Saaty 1990); 
* Construction of a reciprocal matrix by comparing the weights between the attributes of the model. The degree of relative priority of one criterion to another is calculated by assigning weights to each of them from 1 to 9, where 1 indicates that both criteria are equally important, and 9 indicates extreme importance of one criterion over another. A reciprocal value is given to the other criterion in the pair. Furthermore, the ratings are normalized and averaged with the goal of obtaining an average weight for each criterion in the model;

Aggregation of the weights of the elements that provide the best alternative in the model. After all elements and priorities are determined in the model, the ones that are less important for the overall goal can be removed from the model.

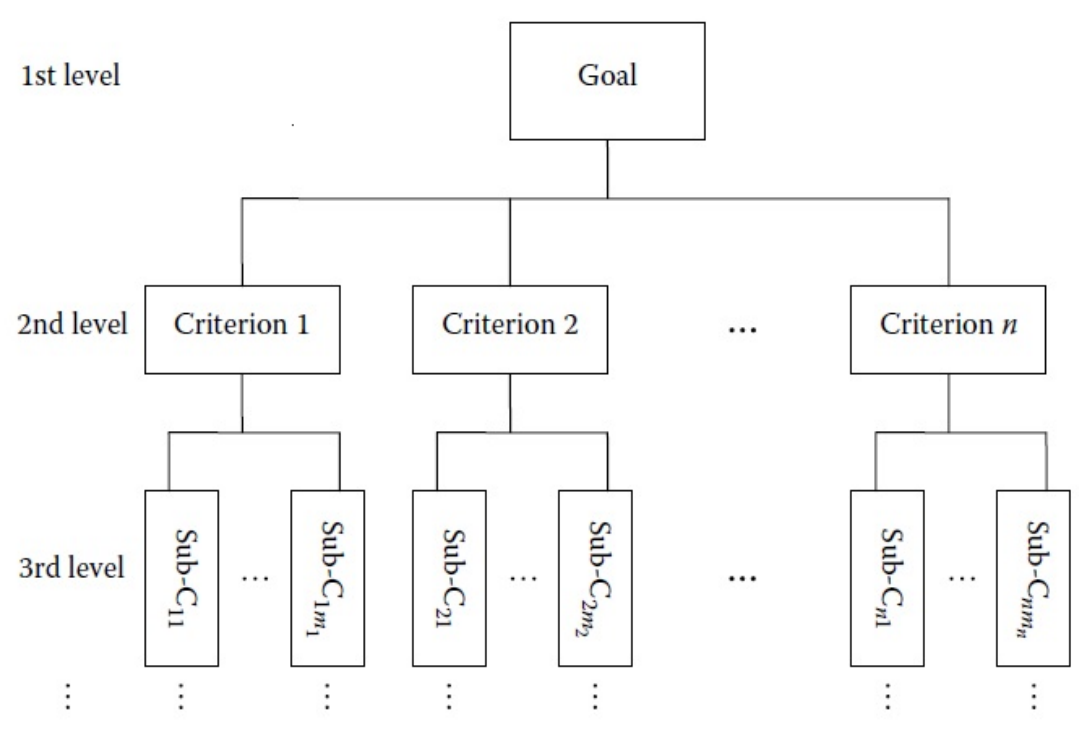

Figure 3.4 The scheme of the AHP (Tzeng and Huang 2011)

Mathematically expressed, having the set of attributes $A=a_{1}, a_{2}, \ldots, a_{n}$ and appropriate weights $\mathrm{w}_{1}, \mathrm{w}_{2}, \ldots, \mathrm{w}_{\mathrm{n}}$ allow a decision maker to perform pairwise comparisons, which are represented by the following matrix (Tzeng and Huang 2011): 


$$
A=\left[\begin{array}{lll}
a_{11} & a_{1 j} & a_{1 n} \\
a_{i 1} & a_{i j} & a_{i n} \\
a_{n 1} & a_{n j} & a_{n n}
\end{array}\right] \quad a_{i j}=\frac{1}{a_{j i}}
$$

Next, the weight matrix $\mathrm{W}$ appears as:

$$
\begin{aligned}
& \begin{array}{lll}
\mathbf{W}_{\mathbf{1}} & \mathbf{W}_{\mathbf{j}} & \mathbf{W}_{\mathbf{n}}
\end{array}
\end{aligned}
$$

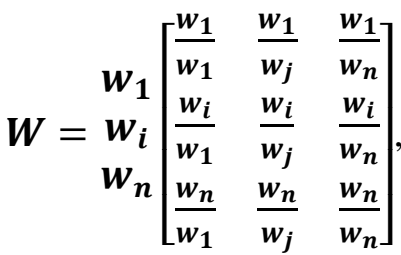

and finally multiplying $\mathrm{W}$ with w gives:

$$
\begin{aligned}
& \begin{array}{lll}
\mathbf{w}_{1} & \mathbf{w}_{\mathbf{j}} & \mathbf{w}_{\mathbf{n}}
\end{array} \\
& W x w=\begin{array}{l}
w_{1} \\
w_{i} \\
w_{n}
\end{array}\left[\begin{array}{lll}
\frac{w_{1}}{w_{1}} & \frac{w_{1}}{w_{j}} & \frac{w_{1}}{w_{n}} \\
\frac{w_{i}}{w_{1}} & \frac{w_{i}}{w_{j}} & \frac{w_{i}}{w_{n}} \\
\frac{w_{n}}{w_{1}} & \frac{w_{n}}{w_{j}} & \frac{w_{n}}{w_{n}}
\end{array}\right]\left[\begin{array}{l}
w_{1} \\
w_{j} \\
w_{n}
\end{array}\right]=n\left[\begin{array}{l}
w_{1} \\
w_{j} \\
w_{n}
\end{array}\right]
\end{aligned}
$$

which represents the final scores for the given alternatives. In this research, this final step was not performed.

Furthermore, in order to establish the consistency of the subjective judgment and consistency of comparative weights, the consistency index (C.I) and the consistency ratio (C.R.) should be calculated. Mathematical expressions for these two indices are expressed as:
C.I. $=\frac{\left(\lambda_{\max }-n\right)}{(n-1)}$
C. R. $=\frac{\text { C.I }}{\text { R.I }}$ 
where:

$\lambda_{\max }$ shows the largest eigenvalue,

$\mathbf{n}$ is the number of attributes, and

R.I. is the random consistency index.

The R.I is made from randomly generated reciprocal matrices. Its values are shown in Table 3.2 for different size of the matrices. According to Saaty (1990), the consistency ratio should not exceed $0.1(10 \%)$ for a valid result.

Table 3.2 Values of random consistency index for different size matrices

\begin{tabular}{ccccccccc}
\hline $\begin{array}{c}\text { No. of } \\
\text { elements }\end{array}$ & $\mathbf{3}$ & $\mathbf{4}$ & $\mathbf{5}$ & $\mathbf{6}$ & $\mathbf{7}$ & $\mathbf{8}$ & $\mathbf{9}$ & $\mathbf{1 0}$ \\
\hline R.I. & 0.52 & 0.89 & 1.11 & 1.25 & 1.35 & 1.40 & 1.45 & 1.49 \\
\hline
\end{tabular}

As already explained, the application of AHP starts with pairwise comparisons among criteria and creates a matrix from which the decision maker calculates the eigenvector, and finally the weight of each criterion.

For evaluation of operators and their ranking, the criteria measured were rope shovel parameters relevant for changing of optimization functions. The main steps that were involved in the application of AHP method in this research are:

Step 1: Building a square matrix that would contain the same criteria in rows as well as in columns. In this particular case, a 3 x 3 matrix was created.

Step 2: Using a preference scale, the decision maker performs pairwise comparisons among criteria, looking at the overall goal as a reference. The preference scale is shown in the table 3.3 . 
Table 3.3 Preference scale for scoring the criteria in AHP (Mulier 2011)

\begin{tabular}{cc}
\hline $\begin{array}{c}\text { Preference judgment } \\
\text { Both of criteria are equally important }\end{array}$ & Ranking \\
\hline $\begin{array}{l}\text { One criterion is more important than the other } \\
\text { One criterion is strongly more important that } \\
\text { the other }\end{array}$ & 5 \\
$\quad \begin{array}{l}\text { that the other } \\
\text { One criterion is very strongly more important } \\
\text { the other }\end{array}$ & 7 \\
One criterion is extremely more important that & 9 \\
\hline
\end{tabular}

The AHP matrix used in this research is presented in Table 3.4. Obviously, the same criteria compared among themselves have the same importance, so the preference score of 1 is the diagonal of the comparison matrix. For instance, fill time is assessed to be more important than the cycle time regarding the goal; thus, conversion of that preference judgment would be value of 3 from the preference score table. Accordingly, cycle time gets a reciprocal value of $1 / 3$ in comparison with fill time. The rest of comparisons were performed in the same manner.

Table 3.4 Comparison matrix of the criteria in the model

\begin{tabular}{c|ccc}
\hline $\begin{array}{c}\text { Comparison } \\
\text { Matrix }\end{array}$ & $\begin{array}{c}\text { CT } \\
\text { (sec) }\end{array}$ & FT (sec) & VB (yd3) \\
\hline CT (sec) & 1 & $1 / 3$ & $1 / 5$ \\
FT (sec) & 3 & 1 & $1 / 2$ \\
VB (yd3) & 5 & 2 & 1 \\
\hline
\end{tabular}


The particular values in the matrix were selected by prior analyzing of the data, and by looking at the importance of variables in the regression model. Volume of the material in the bucket is the most important parameter for both of the models. Therefore, it gets the highest score compared to the other criteria in the model. The other parameter that is also important for the goal is fill time, so it also has a high score compared to the other criteria. The least significant is the criterion number of working hours, which score is the lowest comparing to all other criteria. This criterion is omitted from the model since all operators are leveled on an hourly basis.

Step 3: Summation of all elements in each of the columns, and then dividing elements of every column with the value that represents the sum of that column. Summation of the numbers calculated in the latter way must be equal to 1 . If that number is different, the calculation is not valid.

Step 4: Summation of all elements in each row should be calculated, and then the mean value of every row should be determined. Those mean values represent normalized eigenvectors. In this way, the values of the importance of each criterion are determined.

\subsubsection{Basic principles of PROMETHEE II method}

Depending on the nature of the problem that has to be solved, there are three basic approaches to MADM solutions (Nikolic and Borovic 1996):

\footnotetext{
* ranking of all alternatives from "the best" to "the weakest",

* selection of one - "the best" alternative, and

selection of multiple alternatives.
} 
Considering the goal of this research, ranking of alternatives from "the best" to "the weakest” is an appropriate approach to solving the problem. In order to accomplish this goal, outranking MADM methods are suitable. Outranking methods compare alternatives based on their preference relations.

There are several different types of outranking methods (ELECTRE, PROMETHEE etc.). For this research, the PROMETHEE method was used because it is easy to construct and easy for decision makers to use. There are several types of PROMETHEE methods; each of them has a particular purpose. For the need of this research, PROMETHEE II was used because it provides complete ranking of alternatives.

Consider a MADM problem defined with equation 3.9. At first, pairwise comparisons of alternative a and alternative b should be performed, and if the result is such that $f_{j}(a) \geq$ $f_{j}(b)$, for $\mathrm{j}=1$ to $\mathrm{n}$; then a dominates $\mathrm{b}$. The basic concept of this family of methods has three aspects:

Generalization of the criteria, which involves introduction of the preference function. The preference function is formulated in the following way (Brans and Mareschal, 1990):

$$
\begin{aligned}
& P\left(a_{i}, a_{j}\right)=\left\{\begin{array}{c}
0, \text { if } f\left(a_{i}\right) \leq f\left(a_{j}\right) \\
P\left(f\left(a_{i}\right)-f\left(a_{j}\right)\right), \text { if } f\left(a_{i}\right)>f\left(a_{j}\right)
\end{array}\right\}, \\
& 0 \leq P\left(a_{i}, a_{j}\right) \leq 1,
\end{aligned}
$$

where the difference between two alternatives is calculated as $d\left(a_{i}, a_{j}\right)=f\left(a_{i}\right)-f\left(a_{j}\right)$, with the leveling of the measurement units. The authors of this method proposed six 
types of preference functions, which should cover the most of the cases that appear in the practice. Basically, the decision maker selects suitable preference function for each criterion and defines additional parameters depending on the type of function. These parameters are different thresholds defined by the decision maker, with which one could give strong or weak dominance of one alternative to another. The preference function of Type I-Usual Criterion was used in this research because the indifference between two alternatives is encountered only when $\left(a_{i}\right)=f\left(a_{j}\right)$. This means that if these two values are different, the decision maker gives the strict preference to the action that has the greater value;

When the preference function is determined for every criterion, all comparisons between alternatives are performed for all criteria in the model. The multi-criteria preference index is defined, to globally compare every pair of alternatives. Mathematical definition of the preference index is defined by (Brans and Mareschal, 1990):

$$
\begin{gathered}
\pi\left(a_{i}, a_{j}\right)=\frac{1}{n} \sum_{j=1}^{n} f_{j}\left(a_{i}, a_{j}\right) \\
\pi(a, b)=\sum_{j=1}^{n} w_{j} f_{j}\left(a_{i}, a_{j}\right)
\end{gathered}
$$

where the equation (3.17a) is used when all criteria are equal, and the equation (3.17b) counts criteria weights, which can be determined by AHP. Values range for preference index is from zero to one. 
Evaluation of the alternatives of the set A is performed by using the outranking relation, through preference flows. The positive preference flow $\phi^{+}(\mathrm{a})$ shows how a certain alternative is outranking all the other alternatives while negative performance flow $\phi^{-}(\mathrm{a})$ shows how a certain alternative is outranked by all the other alternatives. Finally, the net flow $\phi(a)$ represents the difference between positive and negative flow, and it is used for determination of the total ranking of alternatives. In PROMETHEE methods, the higher the positive flow and lower the negative flow, the better the alternative. Mathematical formulation of flows as well as final outranking is defined with the equations 3.18 (Brans and Mareschal, 1990).

$$
\begin{gathered}
\phi^{+}(a)=\sum_{a_{j} \epsilon A} \pi\left(a_{i}, a_{j}\right), \\
\phi^{-}(a)=\sum_{a_{j} \epsilon A} \pi\left(a_{j}, a_{i}\right) \\
\phi(a)=\phi^{+}(a)-\phi^{-}(a),
\end{gathered}
$$

where:

$\boldsymbol{\phi}^{+}(\boldsymbol{a})$ represents the positive flow,

$\boldsymbol{\phi}^{-}(\boldsymbol{a})$ represents negative flow, and

$\boldsymbol{\phi}(\boldsymbol{a})$ represents net flow.

Complete order $\left(\mathrm{P}^{\mathrm{II}}, \mathrm{I}^{\mathrm{II}}\right)$ is measured by the net flow (Brans and Mareschal 1990): 


$$
\begin{aligned}
& a_{i} P^{I I} a_{j}\left(a_{i} \text { outranks } a_{j}\right), \text { iff } \phi\left(a_{i}\right)>\phi\left(a_{j}\right) \\
& a_{i} I^{I I} a_{j}\left(a_{i} \text { is indifferent } a_{j}\right), \text { iff } \phi\left(a_{i}\right)=\phi\left(a_{j}\right),
\end{aligned}
$$

For the ranking and evaluation of operators, the criteria are the same as those used in setting up the AHP model. The weights of each criterion were integrated in the set-up of the PROMETHEE II model. This outranking MADM model has following steps in solving the problem (Mulier 2011):

Step 1: Construction of the decision matrix, which will have alternatives in rows, and attributes in columns. The dimension of the decision matrix is $4 \times 3$. Alternatives in this model are: Operator A, Operator B, Operator C, and Operator D. The criteria (attributes) in the MADM model, as already mentioned, are fill time (sec), cycle time (sec), and volume of the material in the bucket $\left(\mathrm{yd}^{3}\right)$.

Step 2: Specification of the weight of each criteria, which in this case, as already explained, were obtained with AHP.

Step 3: Specification of the preference with regard to maximization or minimization of the attribute.

Step 4: Selection of the preference function that is the most suitable with the particular data. The preference function selected for this research is Type 1: Usual Criterion. This type of function does not need any addition parameters to be defined. If some other type of function is selected, the additional preference thresholds should be determined.

Step 5: Comparing the first two alternatives with respect to the first criterion in the matrix. Basically, all pairwise comparisons were done among all alternatives considering all 
criteria, and appropriate scores were established. Scores depend of type of the preference function, and values of thresholds, if any.

Step 6: The scores were then multiplied with the weight assigned to that attribute. Values relevant to the particular pair of alternatives obtained in the previous step were then added row-wise and column-wise (negative and positive flow).

Step 7: Determining the square matrix of preference indices, with alternatives in rows and alternatives in columns. The score for the same alternatives in this matrix is zero; scores for different alternatives are the values obtained in Step 6.

Step 8: Calculation of net flow for each alternative. The alternative that has the highest net flow is clearly "the best," and the other values of flow allow the ranking of rest of alternatives, by decreasing value.

Step 9: If some other type of function than Type 1 is selected, the sensitivity analysis should be performed though variation of thresholds.

Since manual calculation of all steps can be fairly complicated and prone to mistakes, the software PROMETHEE-GAIA should be used for derivation of the final ranking of alternatives. Since there are not a lot of criteria and alternatives in this research, the overall ranking was performed by manual calculations as well as with the software. 


\section{Chapter 4}

\section{Results and Discussion}

\subsection{Mine description}

Data used in this research were provided by a surface coal mine located in the southern United States. The mine is operated by the largest lignite producer in the United States. The company produces more than 33 million tons of lignite on an annual basis, with mining operations in multiple states.

This particular mine operates in an area of 5,809 acres, with over 200 million tons of minable lignite. It delivers approximately 3.5 million tons of coal per year, and approximately 42 million cubic yards of overburden.

The lignite was formed in a geologically complex environment (delta or fluvial conditions), in which various series of flooding and stream channel migration developed. Also, this mine has high annual precipitation with more than 5 feet of rainfall. The mine consists of six minable lignite seams (out of eleven seams), with the average thickness varying from two to six feet. The three shallowest seams do not meet the quality requirement, and thus they are not extracted. The two deepest seams are not mined because of geotechnical and economic constraints. The coal has a mean heating value of 5,120 (BTU/lb). The other quality characteristics of the coal include $43.02 \%$ of moisture, $14.40 \%$ of ash, and $0.67 \%$ of sulfur. Figure 4.1 represents a typical cross section of the mine. 


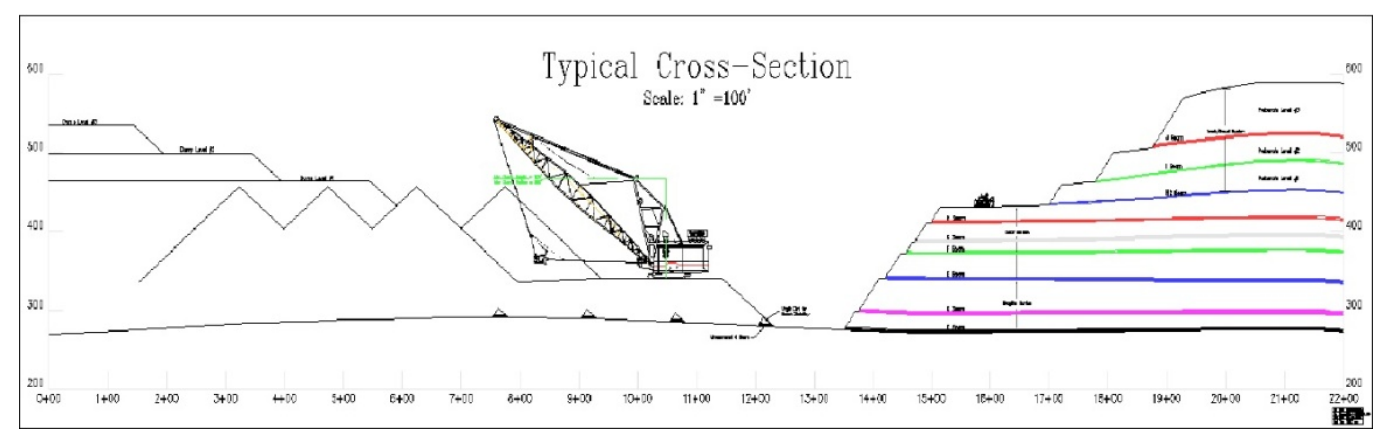

Figure 4.1 Typical cross section of the mine

The mine has approximately 184 employees, operating in two shifts. The equipment operators work in crews. Shovel-truck operations are organized on two eight-hour shifts while dragline operations are performed by two twelve-hour shifts. Shovel-truck crew operations are controlled by one supervisor while none of them is associated with the dragline operations.

The mine uses a truck and shovel fleet composed of a P\&H 2800 XPB (40 $\mathrm{yd}^{3}$ bucket) rope shovel and Caterpillar 789 dump trucks (payload of $180 \mathrm{t}$ ). The rope shovel digs the top material, along with the first two coal seams, up to the top coal seam that is minable. Usually, the shovel removes up to 50 feet of overburden in this stage before reaching the coal. Caterpillar 789 trucks transport overburden to spoil dump areas. Caterpillar D10 dozers disperse the material and bring the surface to the designed topography.

A fleet of four Caterpillar D11 dozers reveals the second, third, and fourth lignite seam, pushing interburden into the former pit. Extraction of the last two feet of interburden is performed by a rubber tire dozer or a Surface Miner (SM). A Marion 8200 dragline with an $82 \mathrm{yd}^{3}$ bucket reveals the fifth and sixth lignite seam. The dragline moves up to $70 \mathrm{ft}$ of dozer-pushed and interburden material. 
A Wirtgen 4200 Surface Miner is used for mining coal seams. Also, as secondary loading equipment, a $19 \mathrm{yd}^{3}$ bucket Komatsu PC2000 excavator is used. Lignite is loaded into 137 tons payload Caterpillar 785 trucks. Ultimately, the coal is crushed and conveyed into two 20,000 tons separate silos. The coal is separated by quality and placed in each of two silos.

Before mining, along with conventional material handling methods, rainfall and underground water must be controlled. Ground stability control is obtained by placing pumps and other underground dewatering systems. In addition, in pre-mining operations, temporary sumps and collection ditches are constructed.

\subsection{Statistical analysis of the measured parameters}

\subsubsection{Cycle time}

As previously mentioned, cycle time represents the essential parameter for estimating loading performance. Basic statistics of overall cycle time, as well as separate cycle times for each operator, for the given data, was performed.

Among different possible ways to graphically represent the data, histogram and boxplot were selected for examining the raw cycle time data (Figure 4.2). A histogram of the raw cycle time data shows that the distribution of the variable is skewed to the right with a single peak (unimodal distribution), and the center of the distribution is around 40 sec (midpoint of the data). The spread of the data ranges from $27.72 \mathrm{sec}$ to 87.27 sec. The tail part of the distribution that shows fairly high values can be seen in the histogram. Likewise, the boxplot 
shows those high values as outliers in the data. Those values can indicate faulty data and were removed from further analysis. The boxplot graph indicates that the median of the raw data for cycle time is about $36.63 \mathrm{sec}$, with $25 \%$ of the observations falling at or below $33.28 \mathrm{sec}$, and $75 \%$ of the data falling at or below $42.84 \mathrm{sec}$.

However, the minimum and maximum values of this particular data do not describe the spread of the majority of the data; the data between $25 \%$ and $75 \%$ are a more resistant measure of the spread, which can be seen in the boxplot graph. Therefore, the assumption is that the majority of the data is in the range of these values.
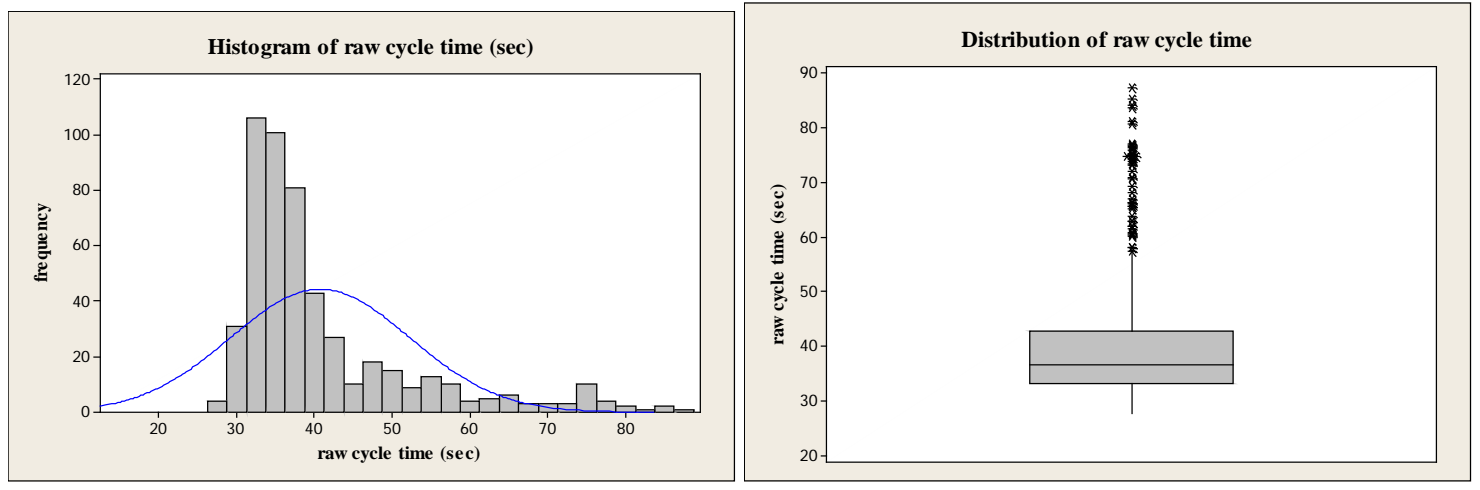

Figure 4.2 Graphical representation of raw cycle time

After the removal of outliers from the data, the corresponding means and standard deviations of cycle time for each operator are shown in Table 4.1. The boxplot of cycle times for individual operators is presented in Figure 4.3. 
Table 4.1 Mean and standard deviation of cycle time for each operator

\begin{tabular}{c|cc}
\hline Operator & Mean $\boldsymbol{\mu}(\mathbf{s e c})$ & Standard Deviation $\boldsymbol{\sigma}(\mathbf{s e c})$ \\
\hline A & 36.27 & 3.68 \\
B & 34.71 & 3.54 \\
C & 36.17 & 3.76 \\
D & 34.82 & 2.83 \\
Overall & 35.69 & 3.69 \\
\hline
\end{tabular}

The overall mean value for cycle time is $35.69 \mathrm{sec}$ with standard deviation of $3.69 \mathrm{sec}$. Operator B has the lowest mean cycle time (34.71 sec) with standard deviation of $3.54 \mathrm{sec}$. Operator A has the largest mean cycle time (36.27 sec) with standard deviation of 3.69 sec. The smallest standard deviation is characterized by Operator D with mean cycle time of 34.82 sec. The largest standard deviation is characterized by Operator C. This operator has the statistical dispersion equal to the difference between $75 \%$ and $25 \%$ of the observations of 5.48 sec. It can be noticed that operators slightly differ in the mean values of cycle time, as well as in consistency from cycle to cycle.

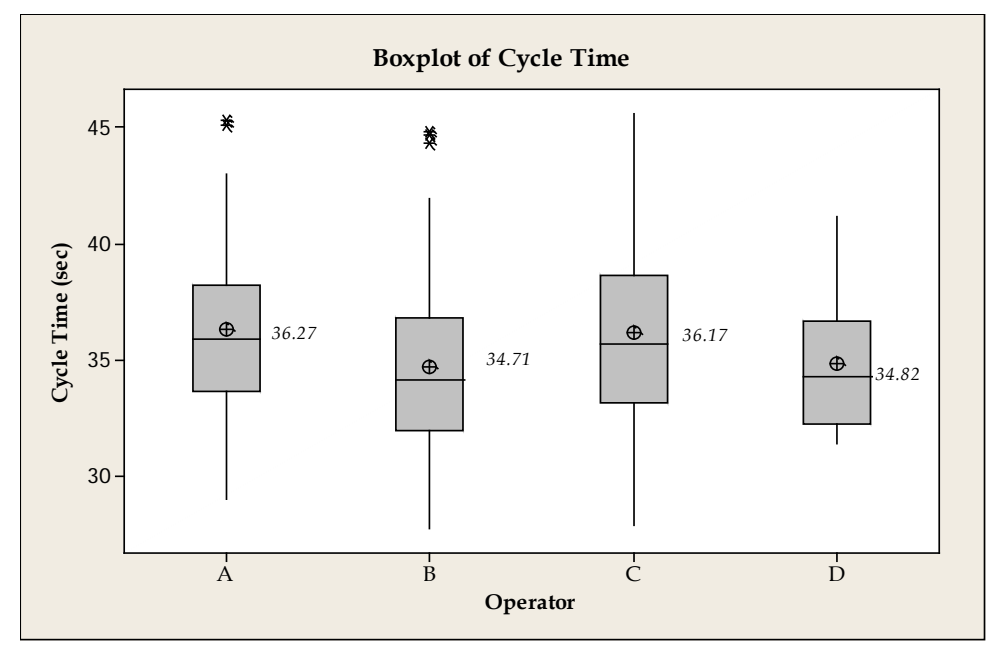

Figure 4.3 Mean cycle time for each operator 
Since cycle time is one of the most influential parameters for production rate, along with fill factor, Figure 4.4 shows the dependency of these three parameters. Values for production rates and fill factors for each operator represent mean values of those parameters. Operator $\mathrm{D}$ has the highest value of mean production rate, highest value of mean fill factor for the second lowest value of mean cycle time. Operator B, who has the lowest mean cycle time, has the second best value of mean production rate, as well as for mean fill factor. Operator A has the highest mean cycle time, the lowest mean production rate, and the lowest mean fill factor, followed by the Operator C. It can be concluded, that considering production rate, Operators D and B have the most preferred performance, followed by Operator C, and the weakest performance was observed for Operator A.

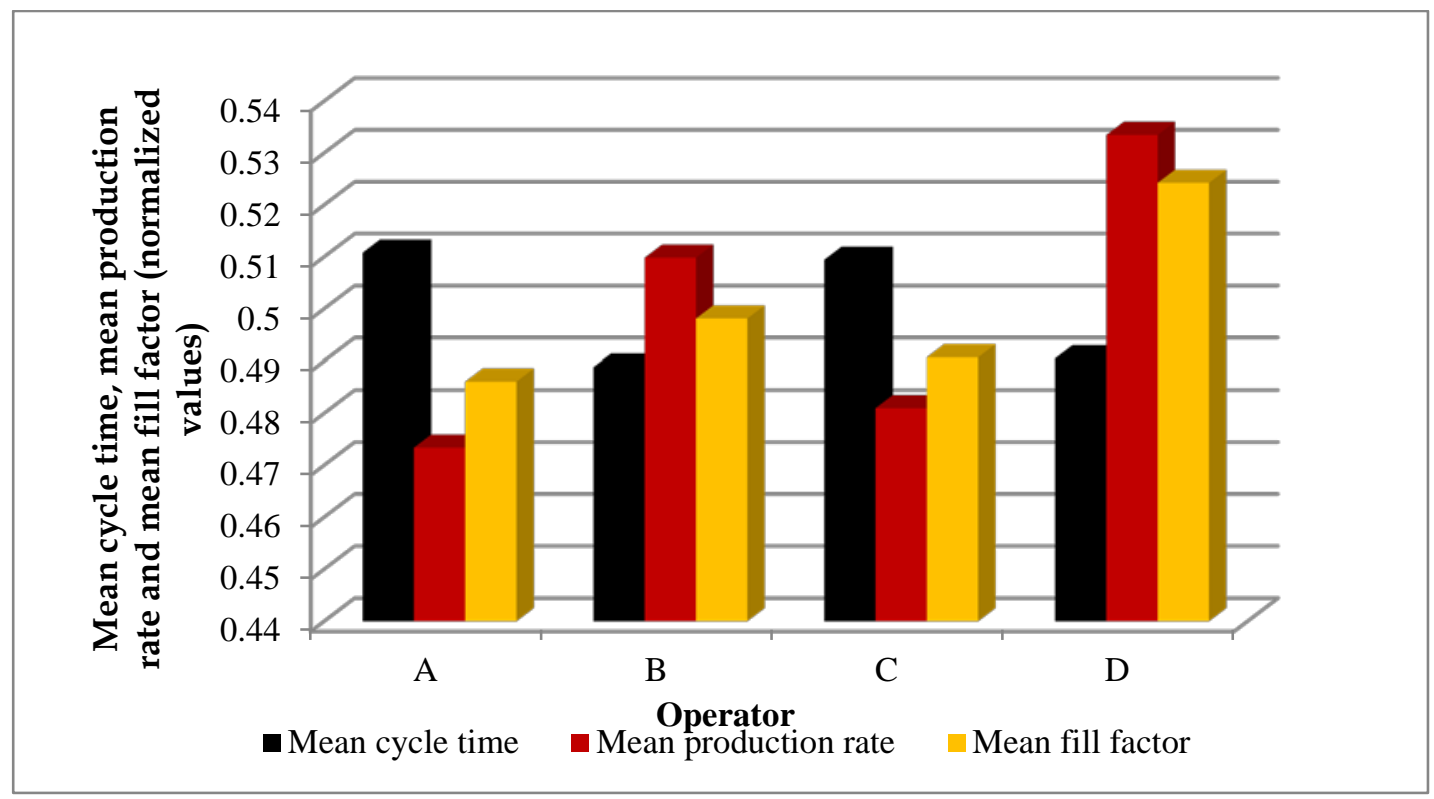

Figure 4.4 Relationship between mean production rate, mean fill factor and mean cycle time for individual operators 


\subsubsection{Fill time}

As already discussed, fill time is the time that the shovel spends in its digging phase during the overall cycle time. Basic statistics of overall fill time, and also separate fill times for each operator, for the given data, was performed. Figure 4.5 shows the histogram and boxplot for the fill-time data obtained for the given shovel.

Histogram of the fill-time data shows that the distribution of the variable is almost symmetric with a single peak. The center of the distribution is around $10 \mathrm{sec}$. The spread of the data is large, from 3.23 sec to 24.41 sec. Outliers can be seen in Figure 4.5; as in the case of cycle time, these are assumed to be faulty data, and were removed from the further analysis.
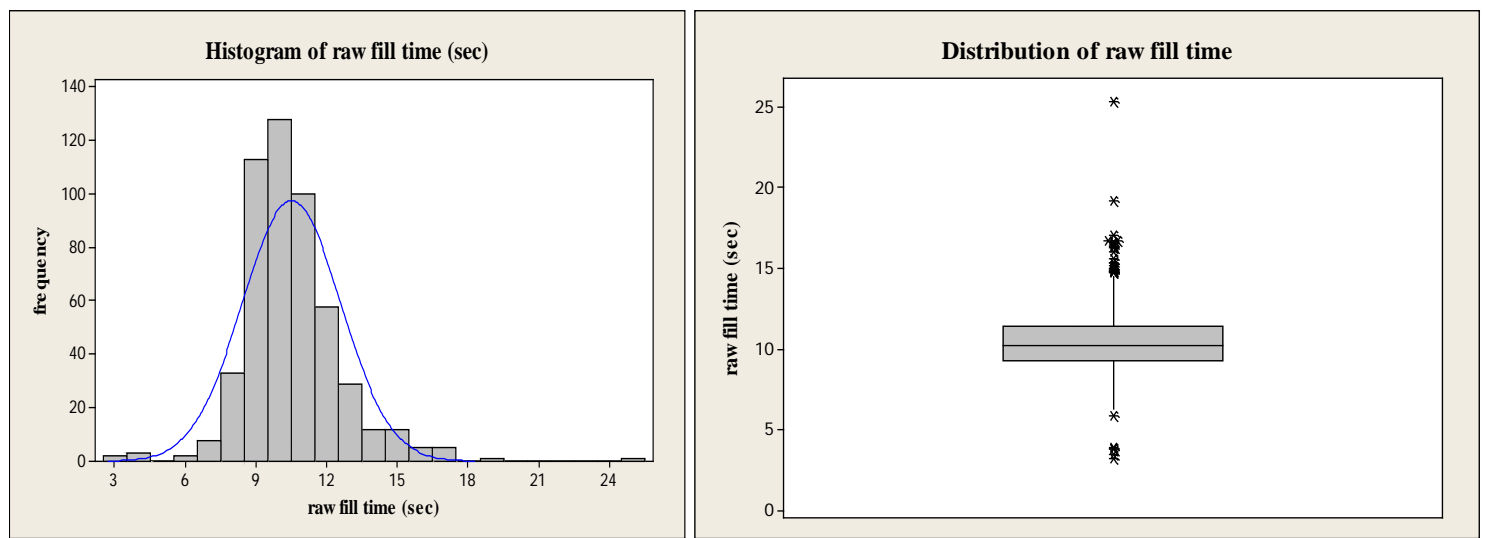

Figure 4.5 Graphical representation of raw fill time

The boxplot indicates the median value of $10.2 \mathrm{sec}$, with $25 \%$ of the observations that fall at or below $9.27 \mathrm{sec}$, and $75 \%$ of the data that fall at or below $11.45 \mathrm{sec}$. As in the case with cycle time, the latter range is considered as the range of the majority of data. 
After the removal of outliers from the data, the corresponding means and standard deviations of fill time were determined, and these are shown in the Table 4.2. The boxplot of fill times for individual operators is shown in Figure 4.6.

The overall mean value for fill time is $10.33 \mathrm{sec}$ with standard deviation of $1.60 \mathrm{sec}$. Operator B has the lowest mean fill time (10.02 sec) with standard deviation of $1.54 \mathrm{sec}$. Operator D has the highest mean fill time $(10.67 \mathrm{sec})$ and the lowest standard deviation of $1.28 \mathrm{sec}$. Operator A has the highest standard deviation $(1.73 \mathrm{sec})$. This operator has the statistical dispersion equal to the difference between $75 \%$ and $25 \%$ of the observations of $1.395 \mathrm{sec}$.

Although there are differences in the mean values of the mean fill time as well as in standard deviations, their values are very small, and it can be concluded that operators are somewhat consistent in their performance.

Table 4.2 Mean and standard deviation of fill time for each operator

\begin{tabular}{c|cc}
\hline Operator & Mean $\boldsymbol{\mu}(\mathbf{s e c})$ & Standard Deviation $\boldsymbol{\sigma}(\mathrm{sec})$ \\
\hline A & 10.84 & 1.73 \\
B & 10.02 & 1.54 \\
C & 10.31 & 1.59 \\
D & 10.67 & 1.28 \\
Overall & 10.33 & 1.60 \\
\hline
\end{tabular}




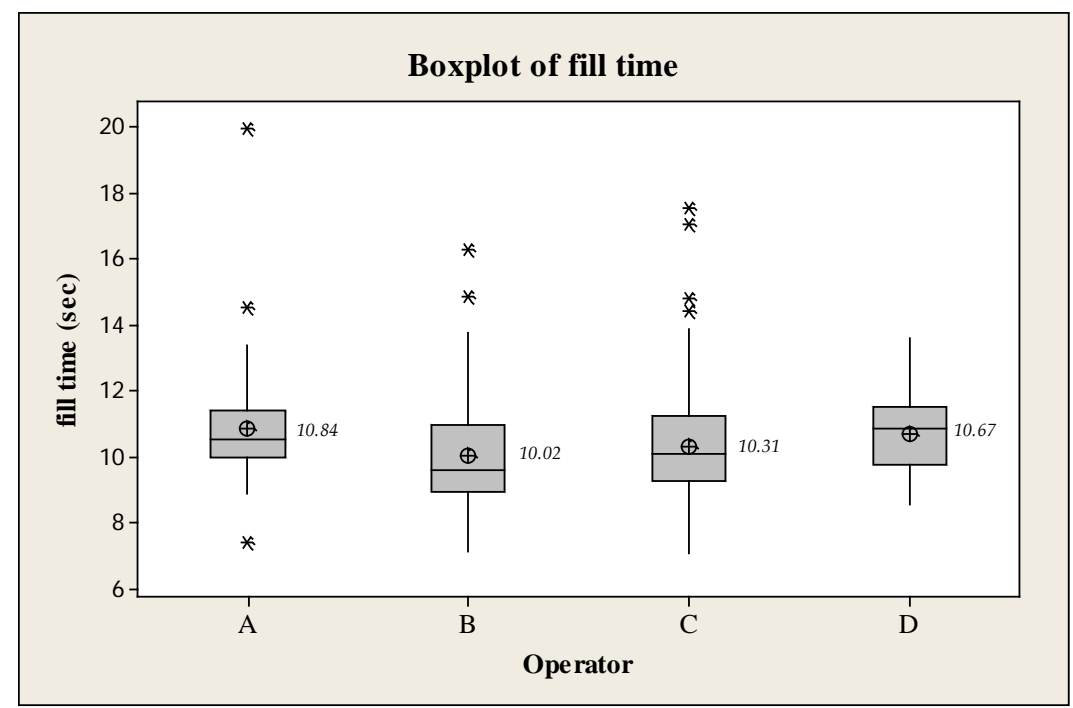

Figure 4.6 Mean fill time for each operator

\subsubsection{Bucket payload}

Statistical analysis of the payload was performed for each operator as well as for the overall variable. Figure 4.7 represents the histogram and boxplot of payload data.
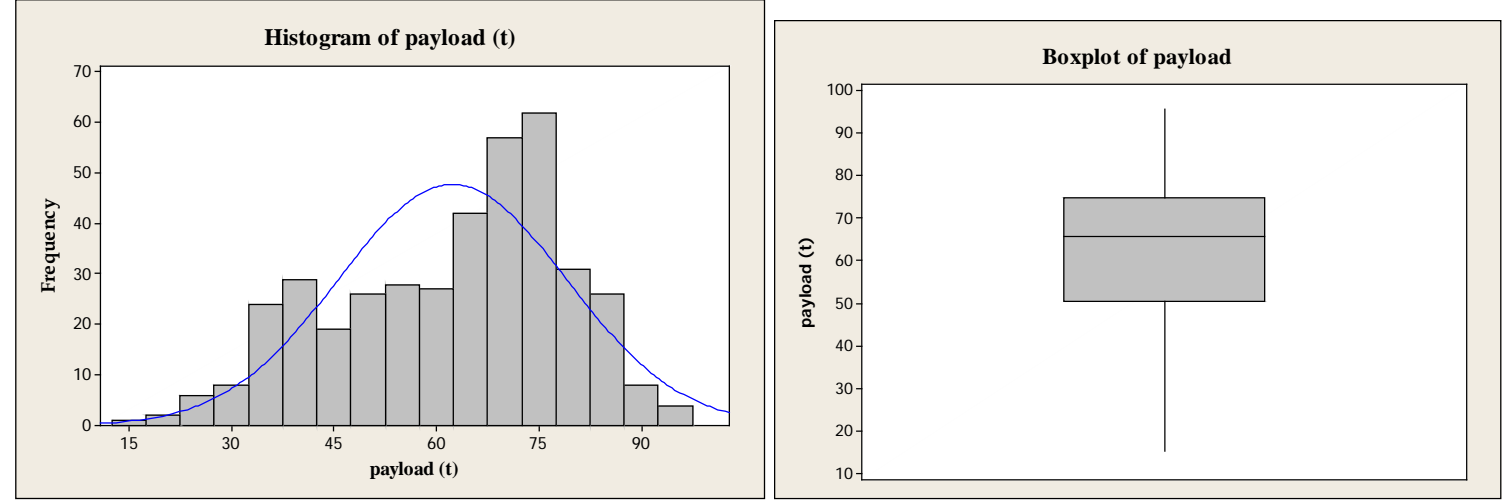

Figure 4.7 Histogram and boxplot of raw payload data

The histogram of payload data indicates that the distribution is more-less skewed to the left to almost symmetric with a single peak, and the center of the distribution is around 62 
tons. The spread of the data is from 15.22 tons to 95.84 tons. As can be seen in the Figure 4.7, there are not any outliers in data. The boxplot shows a median of 66 tons, with $25 \%$ of the data falling at or below 50.58 tons, and $75 \%$ of the data falling at or below 74.85 tons. Mean values, as well as the standard deviation of the measured payload, are presented in Table 4.3. The boxplot of mean payload value for every operator is shown in Figure 4.8.

Table 4.3 Mean and standard deviation of payload for each operator

\begin{tabular}{c|cc}
\hline Operator & Mean $\boldsymbol{\mu}(\boldsymbol{t})$ & Standard Deviation $\boldsymbol{\sigma}(\boldsymbol{t})$ \\
\hline A & 61.36 & 18.24 \\
B & 62.88 & 15.61 \\
C & 61.94 & 17.07 \\
D & 66.18 & 14.25 \\
Overall & 62.36 & 16.68 \\
\hline
\end{tabular}

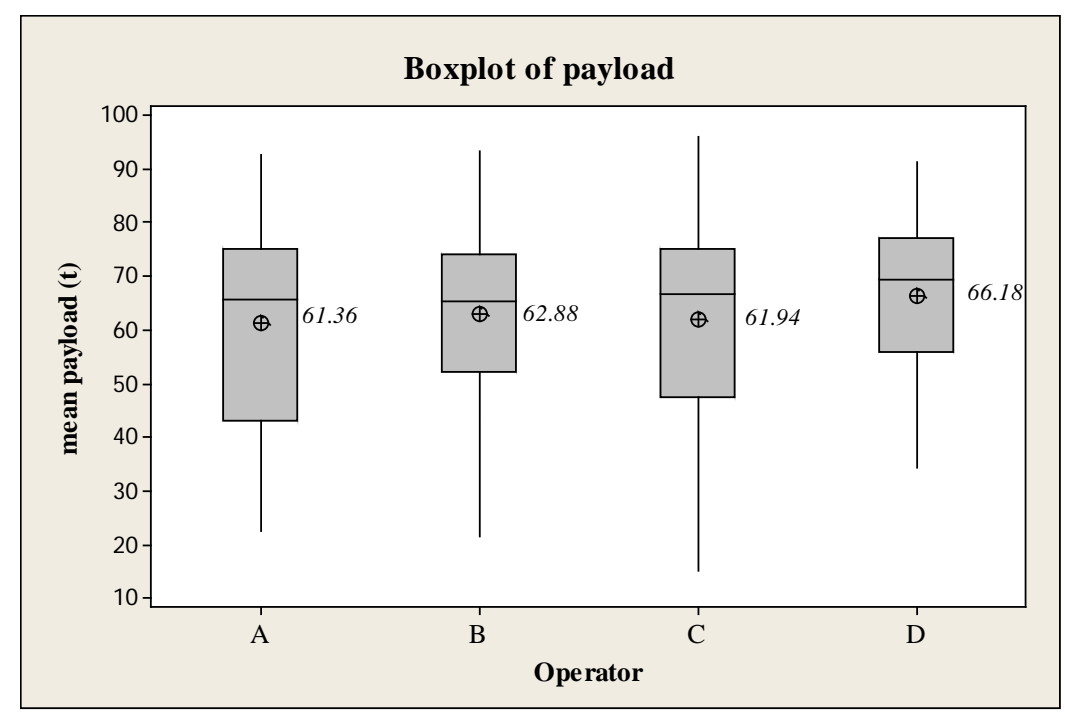

Figure 4.8 Mean payloads for each operator 
The overall mean value for the payload is $62.36 \mathrm{t}$ with standard deviation of $16.68 \mathrm{t}$. Operator $\mathrm{D}$ has the highest mean value of the payload $(66.18 \mathrm{t})$ with the lowest standard deviation. Operator A has the lowest mean payload (61.36 t) with the highest standard deviation compared to all other operators $(18.24 \mathrm{t})$. This operator has the statistical dispersion equal to the difference between $75 \%$ and $25 \%$ of the observations of $31.81 \mathrm{t}$. Considering consistency of operator performance, it is clear from the data that operators differ among themselves. Volume of material in the bucket $\left(\mathrm{yd}^{3}\right)$ is the parameter that is used in further calculations.

\subsubsection{Energy to load a bucket}

The overall parameter of energy to load a bucket, as well as for separate operators, was statistically analyzed. Figure 4.9 represents the histogram and boxplot of energy to load a bucket in unit-less numbers.

The histogram of energy-to-load-a-bucket data shows that the distribution of the variable is roughly symmetric; the center of energy distribution is approximately 14,916 (median $15,525)$
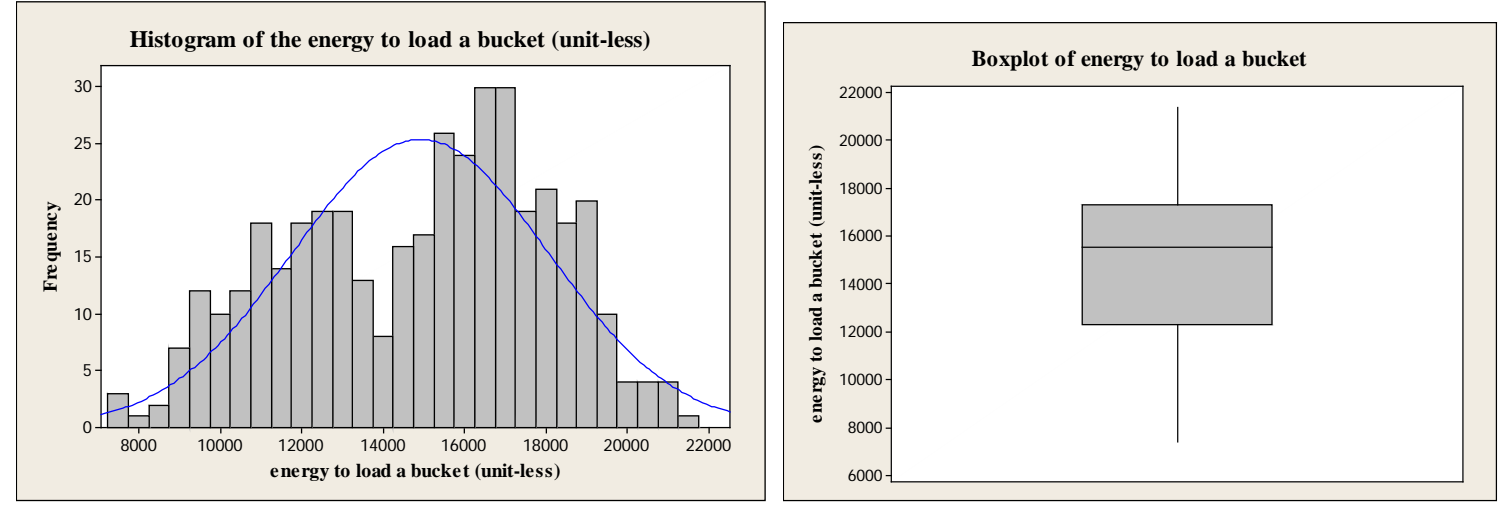

Figure 4.9 Histogram and boxplot of raw energy data 
Twenty-five percent of the observations fall at or below 12,287 , and $75 \%$ of the data fall at or below 17,294. Mean values and standard deviations of the data are shown in Table 4.4, and the boxplot of energy to load a bucket for each operator is presented in Figure 4.10.

The overall mean value for energy to load a bucket is $14,916.11$ with standard deviation of 3,139.10. Operator B has the lowest mean energy to load a bucket $(14,262.49)$ with the lowest standard deviation of 2,964.39. Operator D has the highest mean value of energy to load a bucket, while Operator $C$ has the largest standard deviation of 3,177.44. It can be seen that operators differ in their mean values for this parameter while they are more or less consistent in performance.

Table 4.4 Mean and standard deviation of energy to load a bucket for each operator

\begin{tabular}{c|cc}
\hline Operator & Mean $\boldsymbol{\mu}$ (unit-less) & $\begin{array}{c}\text { Standard Deviation } \boldsymbol{\sigma} \\
\text { (unit-less) }\end{array}$ \\
\hline A & $16,013.67$ & $2,997.93$ \\
B & $14,262.49$ & $2,964.39$ \\
C & $14,788.35$ & $3,177.44$ \\
D & $16,344.00$ & $2,991.38$ \\
Overall & $14,916.11$ & $3,139.10$ \\
\hline
\end{tabular}




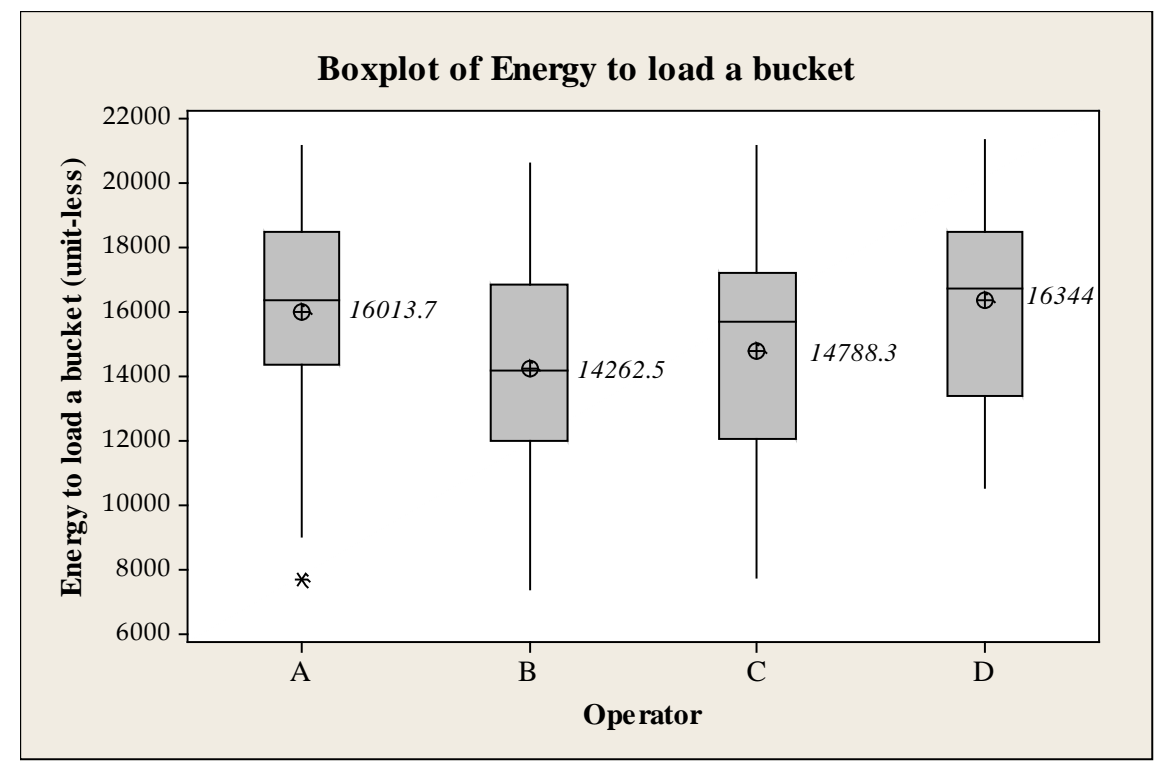

Figure 4.10 Energy to load a bucket for each operator

The relationship between energy to load a bucket and fill time is presented in Figure 4.11.

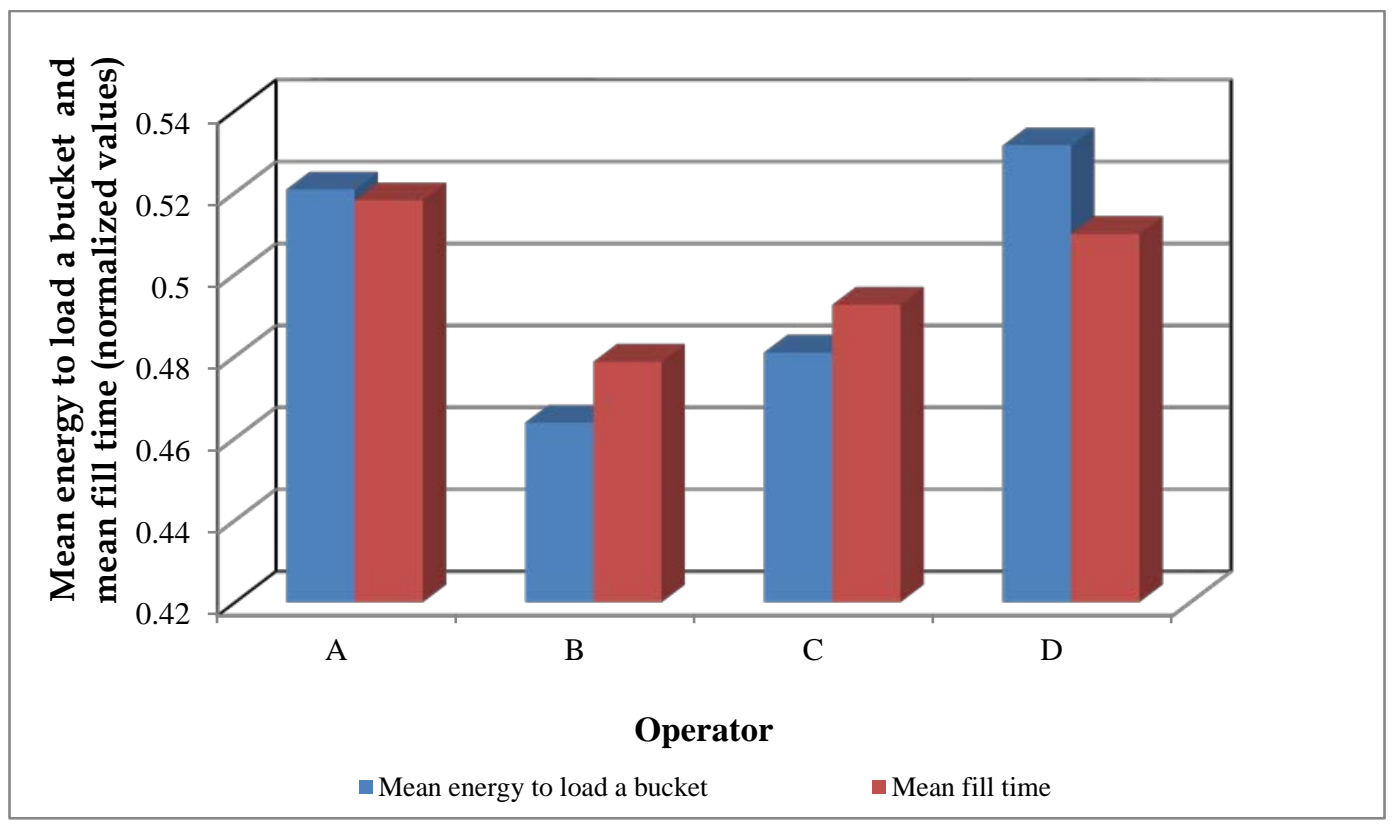

Figure 4.11 Energy to load a bucket and fill time for every operator 
From Figure 4.11 it can be seen that Operator B and Operator C have less energy consumed per fill time while Operator A and D, particularly Operator D, have higher energy consumed per fill time.

The relationship among mean production rate, mean fill factor, and mean energy to load a bucket for individual operators is shown in the Figure 4.12. Operator D has the highest value of mean production rate, highest value of mean fill factor and highest mean value of energy to load a bucket. On contrary, Operator A has the second highest value of mean energy to load a bucket for the lowest mean fill factor and lowest mean production rate. Operator B has the lowest mean energy to load a bucket, with the second best mean production rate and mean fill factor. Considering the ratio between mean production rate, mean energy to load a bucket, and mean fill factor, Operator B seems to have the best performance while Operator A has the weakest.

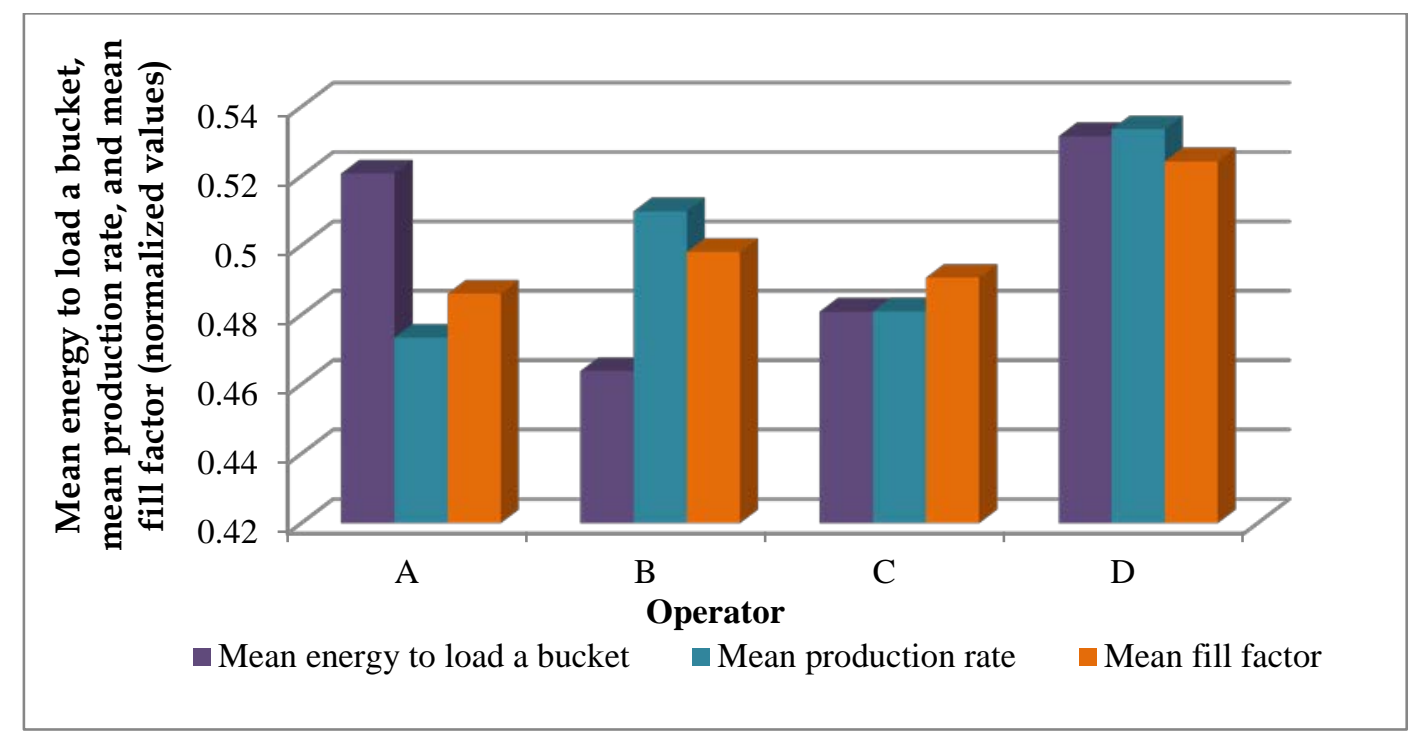

Figure 4.12 Relationship between mean fill factor, mean production rate, and mean energy to load a bucket for each operator 


\subsection{Multiple regression model of energy consumption}

\subsubsection{Correlation among the variables}

The correlation coefficients between the parameters of the given shovel (cycle time, fill time, volume of the material in the bucket, and number of working hours) are shown in Table 4.5. As can be seen from Table 4.5, high correlations between the variables are not observed, except for fairly high correlation between the pair of cycle time and fill time.

Table 4.5 Correlations between fill time, cycle time, volume of the material in the bucket, and number of working hours.

\begin{tabular}{c|ccc}
\hline Correlations & $\boldsymbol{F T}$ & $\boldsymbol{C T}$ & $\boldsymbol{V B}$ \\
\hline CT & 0.511 & & \\
VB & 0.377 & 0.136 & \\
WH & -0.093 & 0.086 & -0.02 \\
\hline
\end{tabular}

\subsubsection{Best subsets and Stepwise regression analysis}

Table 6 shows the results of best subset regression. It can be seen that all four variables participate in the explanation of energy consumption variation. Table 4.7 represents the results of the final model of stepwise regression analysis. The method gave the same preferred model selection as best subset method. One can also see in the output that the variable volume of the material in the bucket has the highest correlation with the energy consumption response and explains the highest portion of variability in it. 
Table 4.6 Results of the best subset regression

\begin{tabular}{c|ccccccc}
\hline Variables & $R^{2}$ & $R^{2}(a d j)$ & $C p$ & $F T$ & $C T$ & $V B$ & $W H$ \\
\hline 1 & 56 & 55.9 & 755 & & & $\mathrm{X}$ & \\
1 & 37.5 & 37.4 & 1223.5 & $\mathrm{X}$ & & & \\
2 & 68.8 & 68.6 & 434.1 & $\mathrm{X}$ & & $\mathrm{X}$ & \\
2 & 59 & 58.8 & 680.5 & & $\mathrm{X}$ & $\mathrm{X}$ & \\
3 & 85.3 & 85.2 & 15.7 & $\mathrm{X}$ & $\mathrm{X}$ & $\mathrm{X}$ & \\
3 & 70.6 & 70.3 & 390.4 & $\mathrm{X}$ & & $\mathrm{X}$ & $\mathrm{X}$ \\
4 & $\mathbf{8 5 . 8}$ & $\mathbf{8 5 . 7}$ & $\mathbf{5 . 0}$ & $\mathbf{X}$ & $\mathbf{X}$ & $\mathbf{X}$ & $\mathbf{X}$ \\
\hline
\end{tabular}

Table 4.7 Stepwise statistical analysis

\begin{tabular}{c|cccc}
\hline Variables & $\boldsymbol{V B}$ & $\boldsymbol{F T}$ & $\boldsymbol{C T}$ & $\boldsymbol{W H}$ \\
\hline $\mathbf{R}^{2}$ & 56.02 & 68.75 & 85.34 & 85.84 \\
$\mathbf{R}^{2}$ (adj) & 55.89 & 68.58 & 85.22 & 84.68 \\
$\mathbf{C p}$ & 755 & 434.1 & 15.7 & 5 \\
\hline
\end{tabular}

\subsubsection{Energy consumption model}

Results of the multiple regression model of energy consumption are shown in Table 4.8 and Table 4.9.

The regression equation has the following form:

$$
Y=(1007.35+56.22 F T-17.68 C T+7.46 V B-8.81 W H)^{2}
$$


Table 4.8 Results of the multiple regression model of energy consumption

\begin{tabular}{c|ccccc}
\hline Term & Coef & SE Coef & T & P & VIF \\
\hline Constant & 1007.35 & 47.7052 & 21.1161 & 0.000 & \\
FT & 56.22 & 3.9984 & 14.0612 & 0.000 & 1.55 \\
CT & -17.68 & 1.4463 & -12.2242 & 0.000 & 1.35 \\
VB & 7.46 & 0.4214 & 17.7115 & 0.000 & 1.12 \\
WH & -8.81 & 3.3420 & -2.6359 & 0.000 & 1.06 \\
\multirow{2}{S}{$\begin{array}{c}\text { Summary } \\
\text { of Model }\end{array}$} & $\boldsymbol{R}^{2}=\mathbf{8 6 . 8 0 \%}$ & $\boldsymbol{R}^{2}(\mathbf{a d j})=\mathbf{8 6 . 3 6 \%}$ & $\boldsymbol{R}^{2}(\mathbf{p r e d})=\mathbf{8 5 . 5 5 \%}$ & $\mathbf{P R E S S = 2 3 8 4 5 9}$ \\
\hline
\end{tabular}

Table 4.9 Analysis of variance table for energy consumption model

\begin{tabular}{|c|c|c|c|c|c|c|c|}
\hline Source & $D F$ & SS & $M S$ & $F$ & $P$ & Variables & Seq SS \\
\hline Regression & 4 & 1432779 & 358195 & 197.253 & 0.000 & FT & 523436 \\
\hline Error & 120 & 217910 & 1816 & & & CT & 324098 \\
\hline \multirow[t]{2}{*}{ Total } & 124 & 1650690 & & & & VB & 572629 \\
\hline & & & & & & WH & 12617 \\
\hline
\end{tabular}

It can be seen from Table 4.8 that hypothesis test of the individual regression coefficients (with t statistic) yields $\mathrm{p}$ values that are all less than 0.005 , which indicates that all of the variables are statistically significant in the model. Also, one of the important tests is to check the values of the VIF. The maximum value of VIF for the model is 1.55 and indicates that multicollinearity is not an issue in this case. The coefficient of determination $\mathrm{R}^{2}$ shows that 
$86.80 \%$ of the variation of the energy consumption is explained with the variables in the model.

Table 4.9 represents the analysis of variance table for the energy consumption model. Analysis of variance indicates that F statistics are very large, and the MSE is small, which further means that the regression line explains the most of variability of the response variable. Comparison of PRESS statistics with SSE is a way of informal judging of sensitivity of the model fit. Value for sum squares of error (error adj. SS in the Table 4.9) is close to the value of the PRESS statistic (Table 4.8), which indicates that over fitting is not the issue in this model. Over fitted models would give small residuals for observations (SSE) in the model, but large residuals for the observations that are predicted (PRESS).

\subsubsection{Validation of the model}

There are a variety of methods that can be used to check the validity of the developed model. Those can be:

* comparison of the prediction of models and coefficients with the theory;

* new data collection for checking model predictions;

* data splitting or cross-validation where part of the data is used for estimation of the model parameters, and the rest of data are used for determining the prediction accuracy of the model.

Some of the methods, including the split sample validation method which was used in this research, have been used more widely than the others. 
The data were divided into two separate samples, with one sample representing data for two operators, and the other sample representing data for the other two operators. Next, one of the samples was used to building the model, and the other sample was used for validation of the model. The best subset regression, as well as the stepwise regression analysis, showed the same subset of the regressor variables for explanation of the energy consumption variability. The parameters of the estimated model, as well as the validation model, are shown in Table 4.10.

Table 4.10 Parameters for the regression and the validation model

\begin{tabular}{c|cc}
\hline Parameters & Validation Model & Estimation Model \\
\hline $\boldsymbol{\beta}_{\mathbf{0}}$ & 946.85 & 1007.35 \\
$\boldsymbol{\beta}_{\mathrm{VB}}$ & 6.43 & 7.46 \\
$\boldsymbol{\beta}_{\mathbf{F T}}$ & 65.25 & 56.22 \\
$\boldsymbol{\beta}_{\mathrm{CT}}$ & -16.83 & -17.68 \\
$\boldsymbol{\beta}_{\mathrm{WR}}$ & -7.85 & -8.81 \\
$\mathbf{M S E}$ & 1857 & 1.816 \\
$\mathbf{R}^{2}$ & $87.82 \%$ & $86.81 \%$ \\
$\mathbf{R}^{2} \mathbf{a d j}$ & $87.61 \%$ & $86.36 \%$ \\
\hline
\end{tabular}

Mathematical formulation for the validation model is represented with Equation 4.2.

$$
\mathrm{Y}=(946.85+65.24 \mathrm{FT}-16.83 \mathrm{CT}+6.43 \mathrm{VB}-7.86 \mathrm{WH})^{2}
$$

It is expected that differences in parameters for these two models exist. However, the following criteria were used for verification of the validation model: 
The overall relationship of the dependent variable and the regressors must be statistically significant for the estimation and the validation models. In this case, the best subset and the stepwise analysis yielded the same results for both models;

* The value of $\mathrm{R}^{2}$ for both models can be different within the range of $\pm 5 \%$. As can be seen from Table 4.10, the difference between these two values is approximately $1 \%$.

\subsection{MADM model}

\subsubsection{Obtaining the weights of the criteria in the MADM model with AHP}

The first two steps in building the AHP model were discussed in Chapter 3. As explained, the third step of the matrix is constructed of the normalized values for the weights that are given in the previous step. Therefore, the normalized comparison matrix for the given MADM model is shown in Table 4.11.

After the summation of the row elements and obtaining of the normalized vector, the weights of the each criterion are given in Figure 4.13. 
Table 4.11 Comparison matrix of the criteria in the model

\begin{tabular}{c|ccc}
\hline Comparison Matrix & CT (sec) & FT (sec) & VB (yd $\mathbf{d}^{3}$ \\
\hline CT (sec) & 0.11 & 0.10 & 0.12 \\
FT (sec) & 0.33 & 0.30 & 0.29 \\
VB (yd $\left.{ }^{3}\right)$ & 0.56 & 0.60 & 0.59 \\
\hline
\end{tabular}

Criteria and weights in the Figure 4.13 are:

Criterion 1 - volume of the material in the bucket $\left(\mathrm{yd}^{3}\right)$, with the weight of $58 \%$;

Criterion 2 - fill time (sec) with the weight of 31\%; and

* Criterion 3 - cycle time (sec) with the weight of $11 \%$.

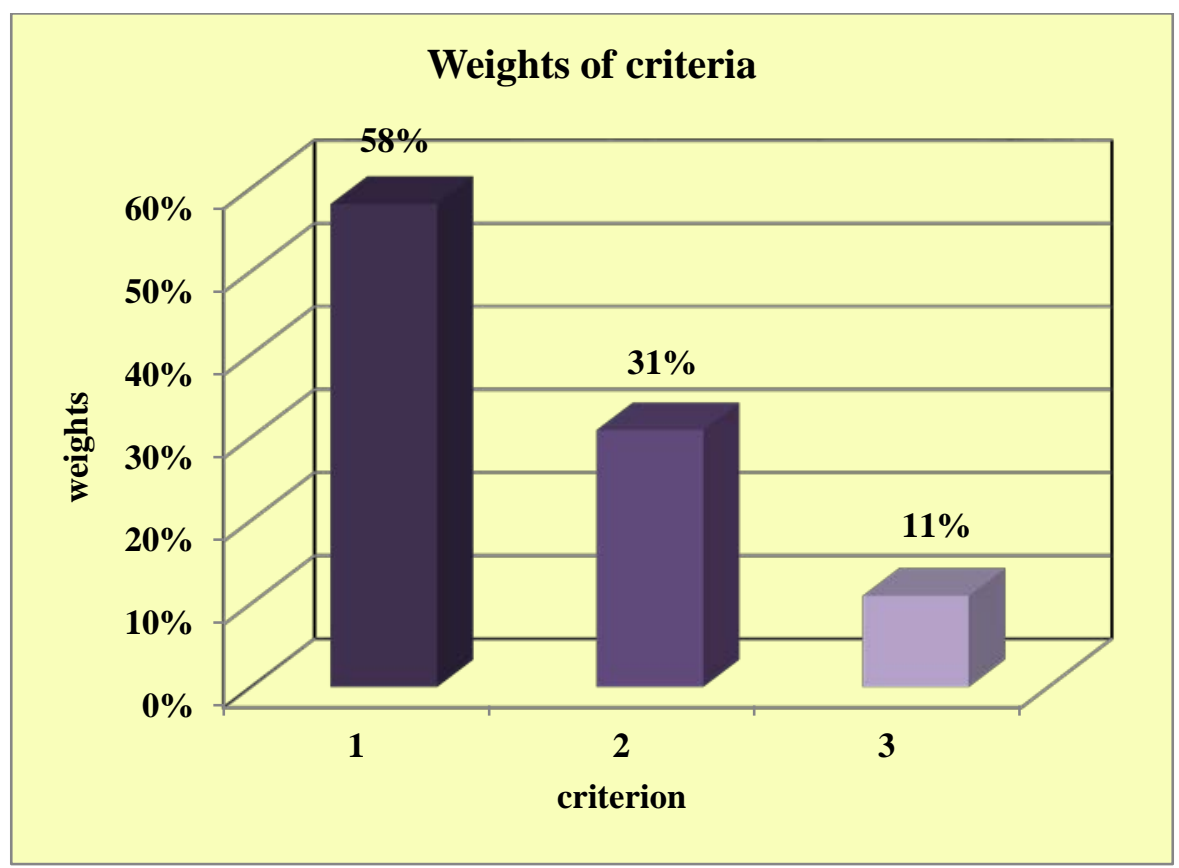

Figure 4.13 Weights of the criteria for the MADM model 
The criterion of volume of material in the bucket is the most important criterion in the model, followed by fill time and cycle time.

To check the consistency of the AHP model, consistency index and consistency ration were calculated. In order to calculate consistency index, the largest eigenvalue $\left(\lambda_{\max }\right)$ should be obtained. The calculation is performed as follows:

$$
\begin{gathered}
{\left[\begin{array}{ccc}
1 & 0.33 & 0.2 \\
3 & 1 & 0.5 \\
5 & 2 & 1
\end{array}\right]\left[\begin{array}{l}
0.11 \\
0.31 \\
0.58
\end{array}\right]=\left[\begin{array}{l}
0.329 \\
0.929 \\
1.747
\end{array}\right]} \\
{\left[\begin{array}{l}
0.329 / 0.11 \\
0.929 / 0.31 \\
1.747 / 0.58
\end{array}\right]=\left[\begin{array}{l}
3.001 \\
3.004 \\
3.006
\end{array}\right]} \\
\lambda_{\text {max }}=\frac{3.001+3.004+3.006}{3}=3.004
\end{gathered}
$$

Calculation of CI by Equation 3.15 as defined in Chapter 3 gives the value of 0.002 . Finally, calculation of the consistency ratio, with the latter value of CI and RI related to size of matrix with three elements (0.52), leads to the value of 0.0038 . This value shows that the CR is less than 1\% (0.38\%). According to Saaty (1990), consistency is satisfactory if the CR is less than $10 \%$. Therefore, consistency doesn't need to be improved in this case.

After obtaining the weights for the criteria, the final MADM model table was created, and it is shown in Table 4.12. The values of the criteria are quantitative values, obtained as the mean values from the measured data of each criterion for each operator. Also, the minimization and maximization of each criterion are indicated, and thus optimal values of each of them are shown. 
It can be seen from Table 4.12 that Operator B had the best performance in fill time and cycle time while Operator D was the most favorable in relation to volume of material in the bucket. Operator A is dominated by all of the other operators. Further analysis is required in order to find the best operator, as well as the rank of each operator.

Table 4.12 Initial data for MADM model

\begin{tabular}{|c|c|c|c|}
\hline \multirow{2}{*}{ MADM } & \multicolumn{3}{|c|}{ Criteria } \\
\cline { 2 - 4 } & fill time (sec) & cycle time (sec) & vol. of the material in the bucket (yd ${ }^{3}$ ) \\
\hline Alternatives & Min & Min & Max \\
\hline Operator A & 10.84 & 36.27 & 38.35 \\
\hline Operator B & 10.02 & 34.71 & 39.30 \\
\hline Operator C & 10.31 & 36.17 & 38.71 \\
\hline Operator D & 10.67 & 34.82 & 41.36 \\
\hline Optimal Values & 10.02 & 34.71 & 58 \\
\hline Criteria Weights & 31 & 11 & \\
\hline (\%) & & & \\
\hline
\end{tabular}




\subsubsection{PROMETHEE II Analysis}

The adjustable decision table for the input data in the PROMETHEE II approach is shown in Table 4.13.

Table 4.13 Input data for PROMETHEE II

\begin{tabular}{|c|c|c|c|}
\hline Action & Max & Min & Min \\
\hline Criteria & VB $\left(y^{3}\right)^{3}$ & FT (sec) & CT (sec) \\
\hline Weights & 0.58 & 0.31 & 0.11 \\
\hline $\begin{array}{l}\text { Type of preference } \\
\text { function }\end{array}$ & Usual & Usual & Usual \\
\hline Form of preference & Shape & Shape & Shape \\
\hline function & 1 & 1 & 1 \\
\hline Thresholds & - & - & - \\
\hline \multicolumn{4}{|l|}{ Alternatives } \\
\hline Operator A & 38.35 & 10.84 & 36.27 \\
\hline Operator B & 39.30 & 10.02 & 34.71 \\
\hline Operator C & 38.71 & 10.31 & 36.17 \\
\hline Operator D & 41.36 & 10.67 & 34.82 \\
\hline
\end{tabular}


The form of the preference function dictates the values for the comparison of criteria. If the criterion is dominated, the value is zero; if it dominates, a value of one is assigned. By multiplying those values by the criterion weight, the preference index is obtained for particular comparison and criterion.

Analysis of the input data starts with pair-wise comparisons. Regarding the first criterion, the volume of material in the bucket (which calls for maximization), each operator was compared to each other. For the first criterion, comparing Operator A with Operator B, Operator A did not dominate; thus, a score of " 0 " was placed in the A/B cell. The comparisons of the Operator A with the other Operators are shown in Table 4.14.

Table 4.14 Comparisons of Operator A with other operators

\begin{tabular}{c|ccc}
\hline Comparisons & Max VB & Min FT & Min CT \\
\hline Operator A - Operator B & 0 & 0 & 0 \\
Operator A - Operator C & 0 & 0 & 0 \\
Operator A - Operator D & 0 & 0 & 0 \\
\hline
\end{tabular}

Likewise, the value of volume of the material in the bucket is not preferable when compared to Operator C and Operator D, and therefore, the same score of " 0 " is in appropriate cells. Next, the values of fill times (which calls for minimization), are compared between Operator A and the rest of operators. It can be seen that Operator A has the least preferable value of fill time; therefore it is scored " 0 ." The same situation arises with cycle time. Finally, the sum of all the scores, sum of positive flow for Operator A, is zero. It can be seen, even in this phase, that Operator A is dominated in all criteria by other Operators. 
Table 4.15 illustrates preference indices of Operator B compared with the other operators. Operator B dominates Operator A in all criteria.

Table 4.15 Comparisons of Operator B with other operators

\begin{tabular}{c|ccc}
\hline Comparisons & Max VB & Min FT & Min CT \\
\hline Operator B - Operator A & 0.58 & 0.31 & 0.11 \\
Operator B - Operator C & 0.58 & 0.31 & 0.11 \\
Operator B - Operator D & 0 & 0.31 & 0.11 \\
\hline
\end{tabular}

Comparing Operator B with Operator C yields the same results as comparing Operating B with Operator A.

However, in comparing Operator B with Operator D for volume of material in the bucket indicates, Operator D dominates Operator B, and therefore the score in the column B/D for that particular criterion is 0 . In all other criteria when compared with Operator D, Operator B dominates. Finally, values of all scores for Operator B are summed by rows, resulting in values that are equal to $1 ; 1$ and 0.42 .

Comparison of Operator C with all other operators are shown in Table 4.16. Comparison of Operator D with all others is illustrated in Table 4.17. The row-wise scores for Operator C are 1; 0; 0.31, while the row-wise scores for Operator D are 1; 0.58; 0.69. 
Table 4.16 Comparisons of Operator $C$ with other operators

\begin{tabular}{c|ccc}
\hline Comparisons & Max VB & Min FT & Min CT \\
\hline Operator C - Operator A & 0.58 & 0.31 & 0.11 \\
Operator C - Operator B & 0 & 0 & 0 \\
Operator C - Operator D & 0 & 0.31 & 0 \\
\hline
\end{tabular}

Table 4.17 Comparisons of Operator D with other operators

\begin{tabular}{c|ccc}
\hline Comparisons & Max VB & Min FT & Min CT \\
\hline Operator D- Operator A & 0.58 & 0.31 & 0.11 \\
Operator D - Operator B & 0.58 & 0 & 0 \\
Operator D - Operator C & 0.58 & 0 & 0.11 \\
\hline
\end{tabular}

If some other type of preference function is selected, the values for the comparison scores are calculated differently for each of them, and calculation can be found in any literature source related to PROMETHEE method. Since only the usual type of function was selected for this research, methods of solving other types of preference functions are not discussed in this research.

The final paired matrix for operator comparison—which yields positive flows, negative flows, and overall flow of each alternative-is shown in Table 4.18. As discussed in Chapter 3, the values of the final flow will give the overall ranking of operators. 
Table 4.18 Paired matrix of alternative comparisons

\begin{tabular}{c|cccccc}
\hline Operator & A & B & C & D & Sum of positive flow & Net flow \\
\hline A & - & 0 & 0 & 0 & 0 & -1 \\
B & 1 & - & 1 & 0.42 & 0.807 & 0.613 \\
C & 1 & 0 & - & 0.31 & 0.437 & -0.126 \\
D & 1 & 0.58 & 0.69 & - & 0.757 & 0.513 \\
Sum of & 1 & 0.193 & 0.563 & 0.243 & & \\
negative flow & & & & & &
\end{tabular}

The overall ranking of operators is shown in Figure 4.14, which is the output of the PROMETHEE-GAIA software. It is represented by the overall flow values. It can be seen from Figure 4.14 that Operator B (overall flow 0.6133) and Operator D (overall flow 0.5133) have close overall flow values, and thus similar performances. On the other hand, Operator A (overall flow -1) has the weakest performance, far below all other operators in the flow chart. This output of performance for the latter operator was strongly indicated by the statistical analysis of the data. Likewise, the best performance of Operator B was strongly indicated as well, besides the lower mean volume of the material in the bucket, where Operator D achieved better performance.

In the future evaluation of operators, it is suggested that the user consult results of the partial ranking with the PROMETHEE I method, which gives comparisons on the positive and negative flows separately. This is because, even though the output of the PROMETHEE II method is not difficult to explain, it provides less information since the differences between positive and negative flows are no longer apparent. Nevertheless, from partial 
ranking, a decision maker can see which of the actions are different to compare, and concentrate on them. The output of the PROMETHEE I method is also available with the PROMETHE-GAIA software. Since in this case, the relationship between operators gave the same results in PROMETHEE I partial ranking, it wasn't shown in this text.

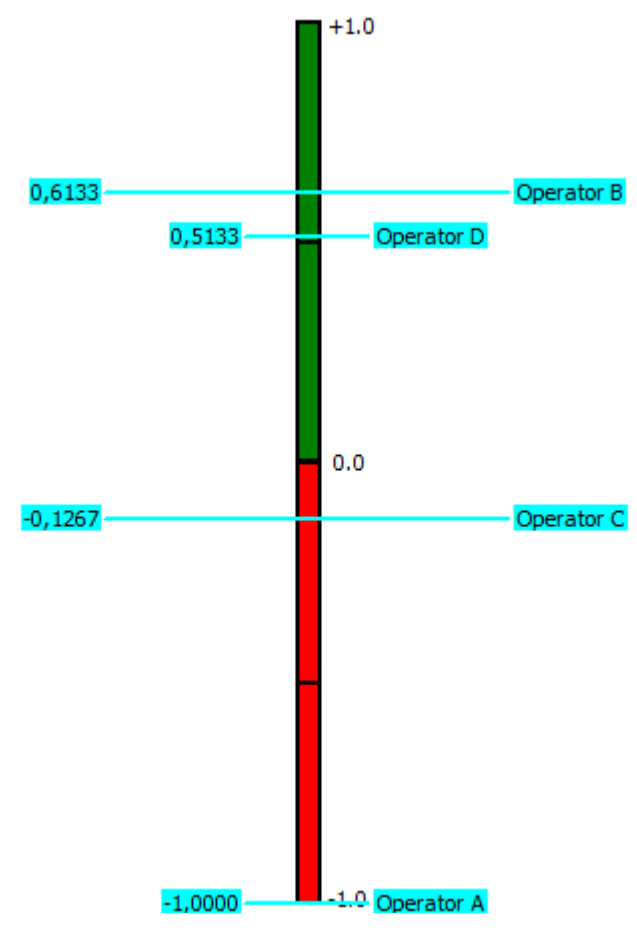

Figure 4.14 Final outranking of operators with flow values

The final ranking of operators is shown in Table 4.19. The operator who demonstrated the best performance, as defined by maximum production and minimum energy consumption — through the analysis of measured volume of material in the bucket, fill time, and cycle time-was Operator B, followed in descending order by Operator D, Operator C, and Operator A. 


\section{Table 4.19 Final ranking of operators}

\begin{tabular}{c|c}
\hline Rank & Operator \\
\hline I & B \\
II & D \\
IV & C \\
& A \\
\hline
\end{tabular}

The variation of operators in various parts of the cycle is evident. Operators who are better in performance could be combined in the same crews with ones who are weaker in performance. However, more data would provide more information about variation between operators.

The parameter that is the most variable is payload of the material. Consequently, operators significantly differ in mean values of production in $\mathrm{yd}^{3} / \mathrm{h}$. Table 20 shows an overview of mean production and energy consumption for shovel operators. The difference between the most productive operator (Operator D) and the least productive one (Operator A) on average is approximately $11 \%$ in productivity. In addition, the difference between the most energy efficient and least energy efficient operator (Operator B and Operator D) is approximately $12 \%$. 
Table 20: Overview of mean production and energy consumption of shovel operators

\begin{tabular}{c|cc}
\hline Operator & Mean production $\left(\mathbf{y d}^{\mathbf{3}} / \mathbf{h}\right)$ & Mean energy consumption (unit-less) \\
\hline A & 3809.64 & $1,589,607.74$ \\
B & 4103.03 & $1,483,074.90$ \\
C & 3870.87 & $1,473,502.03$ \\
D & 4293.33 & $1,689,355.27$ \\
\hline
\end{tabular}




\section{Chapter 5}

\section{Summary, Conclusions, and}

\section{Recommendations for Future Research}

\subsection{Summary}

Since operator practices influence the productivity and energy consumption of rope shovels, the main objective of this research was to develop a model that would help mining professionals evaluate operator performance.

In order to develop a model that would provide operator evaluations, the MADM was applied. Set-up of the model requires definition of alternatives, criteria, preference of criteria, and weights (if necessary). Also, the MADM model - PROMETHEE II was selected as appropriate, considering it provides an overall ranking of the alternatives.

The first step was to determine these MADM decision matrix fields: alternatives, criteria, and weights of criteria. Alternatives were defined as the different operators; different techniques were employed in defining criteria and weights. The model for evaluating operators was performed with the overall goal of minimizing energy consumption and maximizing production rate. The measured parameters taken into consideration were: fill time, cycle time, volume of material in the bucket, and number of working hours.

In order to define which criteria are important and how important they are for the overall goal, mathematical formulation of production rate and energy consumption was required. 
Mathematical formulation of production rate was already known, and the formula for calculating energy consumption was developed with multiple regression analysis. In this phase, the criteria to be used in the MADM model were determined. The values of the criteria are quantitative values, obtained as the mean values from the measured data of each criterion for each operator.

After the models that are relevant for the overall goal were determined, multi-objective optimization was performed in order to prepare the data for further analysis. Multi-objective optimization was performed with the NSGA-II evolutionary algorithm, which is used as a standard approach for solving multi-objective optimization. The variables defined as genes in the software wizard were fill time, cycle time, volume of material in the bucket and number of working hours, with upper and lower bounds defined as their minimum and maximum data values. The only purpose of the optimization was to determine if the measured parameters in both models gravitated toward maximum or minimum values, with respect to minimization of energy consumption and maximization of production rate. Hence, in this phase, min/max preferences of the MADM criteria were determined.

For setting up the suitable weights for the criteria in the MADM model, AHP was used. The values in the AHP matrix were selected by prior analysis of the data, and by looking at the importance of the particular variables in models.

When all necessary parts of the MADM model were determined, the matrix of criteria, attributes, and weights was formed. Another requirement for using PROMETHEE II is to select the preference function for all criteria. In this research, type I preference function was used to compare pairs of alternatives, which gives the strict preference to the alternative that 
has the greater value. All comparisons between alternatives were performed for all criteria in the model. Evaluation of the alternatives by using the outranking relations was performed through their preference flows. The positive preference flow shows how a certain alternative is outranking all other alternatives while negative performance flow shows how a certain alternative is outranked by all other alternatives. Finally, the net flow $\phi(a)$ represents the difference between positive and negative flow, and is used for determination of the total ranking of the alternatives.

\subsection{Conclusions}

Operators and their principal role in performance of the shovel are not frequently considered. A model that analyzes shovel operator performance in different parts of the cycle, with respect to production rate and energy efficiency, was developed in this research. Using this model to gain insight about operator performance, mining professionals can develop methodologies for improving operator productivity. Likewise, they can use this information to develop training for operators who are weaker in performance.

Statistical analysis provided valuable insight about the differences in operator performance in considering different parts of the cycle. The following conclusions can be made:

* Operators slightly vary in mean values of cycle time. Standard deviations are high for each of them, and thus, operators vary in consistency from cycle to cycle.

Differences in mean fill time of operators and standard deviations are small, and therefore operators are consistent in their performance; 
Data for other parts of the cycle time were not available, and thus further inferences about which part of the cycle would be potentially problematic can't be made;

* Operators vary in mean values of payload. Standard deviations in payload between operators are somewhat large, and therefore, it can be concluded that operators vary in consistency in this area;

* Operators vary in mean values of energy to load a bucket. Standard deviations for each of them are not large, and therefore they are more or less consistent in their performance;

The main focus for developing this evaluation model was on finding the most important measured parameters on production rate and energy consumption of the shovel. Considering both of the models with the defined requirements, it can be concluded that:

* The most important parameter for evaluating the performance of operators is volume of the material in the bucket. This parameter is positively correlated with both production rate and energy consumption;

* The second most important parameter for given preferences is fill time.

After analysis of the data, the following conclusions are made about the performance of operators:

* Operator A and Operator C have weaker performance considering measured parameters. Operator A has the weakest performance and is the least consistent operator overall. This evaluation of performance was even obvious in the phase of 
the statistical analysis of data, and it was confirmed with the PROMETHEE-II ranking.

* Operator B and Operator D have the better performance considering measured parameters, and they are fairly similar in performance. Operator B has better performance in almost all analyzed parameters with the given preferences, except mean production rate. On the other hand, Operator $\mathrm{D}$ has the highest mean production rate, but also the highest mean energy consumption. This operator is the most consistent in performance out of all other operators. With just statistical analysis of the data, the clear separation in performance of these two operators could not be performed. PROMETHEE-II identified the operator who is the best in performance for the given preferences, which is Operator B.

The advantages of using PROMETHEE II method can be summarized as follows:

Easy-to-understand, rational model;

Straightforward comparison of pairs of alternatives in the model;

Flexible, allows addition of other criteria for evaluation of operators - not only quantitatively in nature, but also qualitatively;

The disadvantages of the PROMETHEE II method can be summarized as follows:

Subjectivity is involved when selecting criteria weights;

Subjectivity is involved in selecting a preference function, and if selected, function requires determination of thresholds; there is subjectivity involved in choice of them. 


\subsection{Recommendations for further research}

Evaluation of operators in this research was based only on certain parameters that were available for analysis. Collection of more parameters would enhance the accuracy of the evaluation and give better insight into the performance of the shovel. Also, with more data and parameters, mining professionals could use evaluation results to develop training for operators who are weaker in performance.

The additional work of evaluating operator performance could involve evaluation based on changes in the material properties. Also, the extent of the variation between operators could be analyzed on the basis of day vs. night shift, varying weather conditions, etc. Additional experimentation could involve analyzing how different operators' digging styles affect the performance of the shovel. Calculations related to the cost per ton of material would provide additional criteria that could be included in the MADM model. In addition, setting performance targets could lead to a more challenging environment for operators, and thus lift the level of motivation to perform better.

Collecting data on day vs. night shift would allow additional analysis to determine the variation between different shifts, as well between operators in the particular shift. In that way, if the variation was significant, operators who are better in performance could be combined in the same shift with operators who are weaker in performance.

PROMETHEE-II is a method that can be used in any evaluation, and it is powerful since it supports different types of data (qualitative and quantitative). However, the setup of the model in this research can be used for evaluation of operators just for this particular shovel, because of the specific preferences. If it can be concluded, with future experimentation and 
research, that the same preferences for minimizing energy consumption and maximizing production rate can be applied, then this model could be used for other rope shovels, too. 


\section{References}

1. Accuweigh, 2003, “Accuweigh production monitoring system,” Drivers \& Control Services, Texas, USA.

Available at: http://www.drivesandcontrols.com

2. Awuah - Offei, K. and Frimpong, S. 2007, “Cable shovel digging optimization for energy efficiency,” Mechanism and Machine Theory, 42(8):995-1006

Available at: http://dx.doi.org/10.1016/j.mechmachtheory.2006.07.008

3. Awuah - Offei, K. and Summers, D. 2010 "Reducing energy consumption and carbon footprint through improved production practices,” Technical report, Missouri University of Science and Technology,

Available at: www.icci.org/reports/10Awuah-OffeiER9.pdf

4. Back T., Hammel, U. and Schwefel, H.P. 1997, “Evolutionary computation: Comments on the history and current state," IEEE Transactions on Evolutionary Computation, 1(1):3-17.

Available at: http://ieeexplore.ieee.org/stamp/stamp.jsp?tp=\&arnumber=585888

5. Balaji, M. and Kamaraj, V. 2012, "Evolutionary computation based multi-objective pole shape optimization of switched reluctance machine," Electrical Power and Energy Systems 43(1):63-69.

6. Bascetin, A. 2003, “A decision supporting system for optimal equipment selection in open pit mining: analytical hierarchy process,"

Available at: www.istanbul.edu.tr/eng/jeoloji/library/dergi/dl/?cilt16-s2-syf(1-12)

7. Bascetin, A. 2006, “A decision support system using analytical hierarchy process (AHP) for the optimal environmental reclamation of an open-pit mine," Environmental Geology, 52(4):663-672.

8. Bernold, L. 2007, “Quantitative Assessment of Backhoe Operator Skill,” J. Constr. Eng. Manage., 133(11):889-899.

9. Bogunovic, D. 2008, “Integrated Data Environment for Analysis and Control of Energy Consumption (IDE-ACE) in Surface Coal Mining" (Doctoral dissertation, The Pennsylvania State University, 2008). 
10. Brans, J. and Mareschal B., 1990, "PROMETHEE Methods," Available at: http://www.inf.unideb.hu/valseg/dolgozok/anett.racz/docs/DSS/Promethee.pdf

11. CareerTech, 2008: "Heavy equipment operation : Operator," Oklahoma Department of Career and Technology Education Stillwater, Oklahoma.

12. Caterpillar, 2010, “Caterpillar performance handbook,” Caterpillar Inc., Peoria, Illinois, USA.

13. Department of Energy 2007, "Mining industry bandwidth study,” Department of Energy, Washington DC, USA.

14. Diwekar, U. 2008, "Introduction to applied optimization,” Second Edition, Springer Science and Business Media, New York, USA.

15. Dover Simulators, 2012, "Electric Rope Shovel," Available at: http://doversimulators.co.za/training-simulators/electric-rope-shovel/

16. Fifth Dimension Technologies, 2011, "Shovel/Excavator Training Simulator," Available at: http://www.5dt.com/products/ishovel06.html

17. Fiscor, S. 2007, "Productivity considerations for shovels and excavators," Available at: http://www.womp-int.com/story/2007vol6/story024.htm

18. Har Hat Training Series, 1990: “Overhead crane operator safety training,”[Sample Broshure], Available at: http://www.osha.com/pdf/Overhead_Crane_Instructors_Notes.pdf

19. Harrell, G. and Daim, T.U. 2010, "HDM modeling as a tool to assist management with employee motivation: the case of silicon forest," Engineering Management Journal, 22 (1):23-33.

20. Kasperczyk, N. and Knickel, K. 2004, “The Analytic Hierarchy Process (AHP),” Available at: http://www.ivm.vu.nl/en/Images/MCA3_tcm53-161529.pdf

21. Kluge, P. and Malan, D.F. 2011, "The application of the analytical hierarchical process in complex mining engineering design problems," Journal of the South African Institute of Mining and Metallurgy, 111(12):847-855.

22. Komljenovic, D. and Kecojevic, V., 2006 "Multi-Attribute selection method for mining trucks," SME Transactions, Society of Mining Metallurgy, and Exploration, 320:94-104. 
23. Komljenovic, D., Bogunovic, D. and Kecojevic, V. 2010, "Dragline operator performance indicator," International Journal of Mining, Reclamation and Environment, 24(1):34-43.

24. Kutner, M. H., Nachtsheim, C.J., and Neter, J. 2004, “Applied Linear Regression Models,” Fourth Edition, McGraw-Hill/Irvin, Inc., New York, USA

25. Lumley, G. 2005, “Reducing variability in dragline operator performance," in Aziz, N (ed), Coal Operators' Conference, University of Wollongong \& the Australasian Institute of Mining and Metallurgy, 2005, 97-106.

26. Madhavan Pillai, E., Paul Robert, T., and Rajmohan, M. 2011, "Study on the Influence of Human Factors on Overall Equipment Effectiveness,” European Journal of Scientific Research 53(2):179-192.

27. Montgomery, D.C. and Runger, G.C. 2003, "Applied Statistics and Probability for Engineers,” Third Edition, John Wiley and Sons Inc., New York, USA.

28. Moore D.S. and McCabe George P. 2006, "Introduction to the practice of statistics," Fifth Edition, W. H. Freeman and Company, New York, USA.

29. Motion Metrics International Corp., 2012, “Advanced monitoring solutions for mining," Available at: http://www.motionmetrics.com/files/brochures/English/MMI_Brochure_Complete.pdf

30. Mulier, N. 2011, "A strategy for using Multicriteria Analysis in Decision-Making, A Guide for Simple and Complex Environmental Projects,” Springer Science and Business Media.

31. Nikolic, I. and Borovic, S. 1996, "Visekriterijumska optimizacija - metode, primena u logistici, softver,” Centar vojnih skola VJ, Beograd.

32. Oborne, D.J. 1993 "Person-Centered Ergonomics: A Brantonian View of Human Factors,” Boca Raton, CRC Press, FL, USA.

33. Patnayak, S. (2006) "Key performance indicators for electric mining shovels and oil sands diggability," (Doctoral dissertation, University of Alberta, 2006).

34. Peterson, D.J, Latourrette, T. and Bartis, J.T 2001, "New forces at work in mining: Industry views of critical technologies,” The Rand Corporation, Washington Available at: http://www.rand.org/pubs/monograph_reports/MR1324.html 
35. P\&H Mine Pro Services, 2001, “Peak performance practices - Dippers,” P\&H Mining Equipment, Wisconsin, USA.

36. P\&H Mine Pro Services, 2003, "Peak performance practices - Excavator Selection," P\&H Mining Equipment, Wisconsin, USA.

37. Robbins, S. P. 2003, “Organizational Behavior,” Tenth Edition, Pearson Education International, New Jersey, USA.

38. Saaty, T. L. 1990, "How to make a decision: The Analytic Hierarchy Process," Available at http://www.elsevier.com/authored_subject_sections/S03/Anniversary/EJOR_free16.pdf

39. Sage, G. H. 1984, “Motor learning and control: A neuropsychological approach,” Wm. Brown, Dubuque, Iowa.

40. Simlog , 2012, “The Standard in Cost-Effective Simulation for Training Heavy Equipment Operators" [Brochure], Available at: $\underline{\text { http://www.simlog.com/pdf/ERS-flyer-e.pdf }}$

41. Sen, C. G. and Cinar, G. 2009, "Evaluation and pre-allocation of operators with multiple skills: A combined fuzzy AHP and max-min approach,” Elsevier, ScienceDirect, 37(3):2043-2053.

42. Song, Y. and Yinghui, H. 2009, "Group Decision-Making Method in the Field of Coal Mine Safety Management Based on AHP with Clustering," Proceedings of the 6th International ISCRAM Conference - Gothenburg, Sweden.

43. Thoroughtec simulation, 2010, "Shovel Simulators, Digger Simulators and Excavator Simulators,” 2010 Thoroughbred Technologies (Pty) Ltd.

Available at:

http://www.thoroughtec.com/cybermine/surface-mining-simulator/shovel-excavatorsimulator.html

44. Thunderbird Mining System, 2012, “Tritronics ShovelPro Monitor” [Brochure], Available at: http://www.tbirdpac.com/shovelsmonitoring/docs/shovelpro.pdf

45. Tzeng, G. and Huang, J. 2011, "Multiple Attribute Decision Making, Methods and Applications,”, CRC Press Taylor \& Francis Group, USA.

46. Vassilev, V., Genova, K. and Vassileva, M. 2005, "A Brief Survey of Multicriteria” Decision Making Methods and Software Systems," Available at: http://www.ivm.vu.nl/en/Images/MCA1_tcm53-161527.pdf 
47. Venkataraman, P. 2003, “Applied Optimization With Matlab Programming,” John Wiley \& Sons, New York, USA.

48. Vista 2012, “Electric Rope Shovel,” VISTA Training, Inc. 721 Cornerstone Crossing Waterford, WI 53185, USA

Available at: http://www.vista-training.com/training/type/simulators/electric-shovel

49. Vista Training, Inc., 2002: “Equipment operator skill-based pay plan (SBPP),"

Available at:

http://www.vista-training.com/assets/pdf/equipment_operator_skill-based_pay_plan.pdf

50. Weiss, D. J., and Shanteau, J. 2003, “Empirical assessment of expertise,” Hum. Factors, 45(1): 104-114.

51. Widzyk-Capehart, E. and Lever, P. 2004, “Towards rope shovel automation operation information system,” CRCMining Conference, Noosa Head, Queensland, Australia.

52. Yavuz, M. 2007, “An Equipment Selection Application Using The AHP Method,” SME Annual Meeting February 25-28 Salt Lake City, Utah.

53. Zitzler, E., Laumanns, M. and Bleuler, S. 2004, “A Tutorial on Evolutionary Multiobjective Optimization,"

Available at: http://www.cs.tufts.edu/comp/150GA/handouts/zitzler04.pdf 